\title{
DE POTOSÍ Y TARIJA A LA FRONTERA CHIRIGUANA
}

\author{
Rodolfo A. Raffino, J. Diego Gobbo \\ y Anahí Iácona
}

\section{I - Advertencia}

Las fuentes históricas generadas en la segunda mitad del siglo XVI contienen datos sobre dos períodos cruciales en la historia regional del sur boliviano y extremo boreal argentino. El primero corresponde a la ocupación Inka ocurrida durante el reinado de Tupa Inka, entre la segunda mitad del siglo XV hasta la caída del Tawantinsuyu en la región, la cual hacemos coetánea con la entrada de Diego de Almagro a Tupiza a fines de 1535, luego a Chicoana del Valle de Lerma en Salta en los primeros meses de 1536 y el pasaje por la cordillera andina por Comecaballos hacia Chile en el otoño de ese mismo año. (Raffino 1995, 43 y 2004, 50-67). ${ }^{1}$

El segundo período se inicia con la primera entrada de los españoles a los valles de Tarija, Chaguaya, Pilaya, Padcaya, Camacho y Antigal: la expedición de Pedro de Candia (el griego) y Diego de Rojas a comienzos de 1539 y tienen hitos significativos durante la gestión del Virrey Toledo y las fundaciones de Santa Cruz de La Sierra por Nuflo de Chávez (1557), Tarija por Luis de Fuentes y Vargas en 1574 y posteriormente Concepción del Bermejo por Alonso de Vera (1585).

Estas fuentes comprenden los trabajos de cronistas como R. Lizárraga (quien estuvo en Talina y Tupiza en su viaje a Chile en 1589), el Memorial de Charcas de 1582 y aportes de corte etnohistórico de Roberto Levillier (1926), Enrique de Gandia (1935), Alberto M. Salas (1945), W. Espinoza Soriano (1969, 1981 y 1986), T. Saignés (1985). F. Renard-Casevits, T. Saignés y A.Taylor (1988), R. Raffino (1993), E. Maeder (1996), A. M Presta (1997 y 2001) y M. Barragán Vargas (2001y 2002).

En lo referente a la problemática arqueológica, los antecedentes regionales corresponden a trabajos realizados a partir del primer tercio del siglo XX hasta tiempos recientes por E. Nordenskiöld (1917 y 1924). A. Métraux (1933). O. Schmieder, (1924). H. Walter (1959), R. Raffino (1981, y 1993), A. Posnansky (1945), P. Delcourt; 2001, V. Lee (1992) y S. Alconini (1993).

Estos entregan evidencias de la conquista y dominio del Tawantinsuyu sobre las naciones que habitaban el altiplano y los valles mesotérmicos del sector meridional de la actual Bolivia y extremo boreal argentino. Un dominio en territorios pertenecientes a organizaciones sociales de tipo cacicazgo, jefatura o señorío, localizadas al S. del antiguo

\footnotetext{
${ }^{1}$ Hemos definido nuestra posición con respecto a la ubicación de Chicoana, la cual y en base a datos confirmados en el terreno, corresponde al mismo lugar donde se encuentra actualmente el Campo del Pucará o de los Túmulos en el Valle de Lerma, donde existen centenares de collcas Inka. El paraje se halla inmediatamente por debajo de la Quebrada del Toro salteña, desde donde desciende el capañam seguido por almagro y sus guías Inka. Ese fue el lugar donde Almagro se detuvo para reaprovisionarse en el verano de 1536 (Rafino; 2004).
} 
Lago Aullagas (hoy Lago Poopó) hasta las regiones de Humahuaca en Argentina. En los actuales Departamentos bolivianos de Potosí, Chuquisaca y Tarija, junto a la sección oriental de las provincias argentinas de Jujuy y Salta, donde habitaron las naciones Quillacas, Azanaques, Carangas, Soras, Yuras, Caracaras, Uruquillas, Chichas, Chuis, Churumatas, Erquis, Tomatas, Coimatas, Juríes, Ocloyas y Omaguacas.

La coordinación de estas fuentes históricas con el registro arqueológico es posible cuando los trabajos de terreno son llevados a cabo por arqueólogos profesionales expertos en la cuestión Inka. En este sentido y para el caso específico del sur boliviano, los aportes de investigadores aficionados locales han carecido de una capacidad diagnóstica que permita discernir cuál es el repertorio arquitectónico Inka del local preexistente (llámese Chicha, Caranga, Erquis, Tomata etc.). Diferencias que se advierten en particular en las guarniciones defensivas para controlar las invasiones chiriguanas, construidas por unos y otros en forma independiente y en diferentes tiempos en algunos ejemplos, o mixta o multicomponente en los que han participado arquitectos cuzqueños y canteros locales en otros.

La ausencia de especialistas ha demorado asimismo la identificación de las diferencias existentes entre el clásico estilo arquitectónico del Tawantinsuyu con el producido por las jefaturas Chicha y otras etnias regionales pre-existentes. Una situación similar acontece con la arquitectura histórica de los primeros momentos de la ocupación regional española. En no pocos casos estos exponentes estructurales son factibles de identificar, como es el de algunos tramos de caminos parcialmente empedrados y de buena factura en Sococha, El Tojo, Rejara y Mecoya entre otras localidades (situados próximos a la frontera argentino-boliviana, al norte de las actuales poblaciones argentinas de Santa Victoria Oeste-Nazareno.-Iruya), pero que no son Inkaicos sino históricos.

Esta situación se repite en el caso de algunos reductos defensivos construidos por las parcialidades locales que son claramente atribuibles a tiempos históricos, como los de Tomatas Grandes (mencionado en las crónicas y atribuidos a la parcialidad homónima) así como a las construcciones de San Lorenzo, Fuerte de Marquiri y Rincón Sola, situados en lo alto de cerros en proximidades de Tarija y Tolomosa. Estos tres reductos carecen de arquitectura militar Inka, por lo que su fundación no responde al mandato del Cuzco. (Cuadro I). También en obras monumentales multicomponentes, como el Puente de Sama, de original factura Inka pero remodelado en tiempos coloniales, entre varios casos más.

Sólo con una buena estrategia observacional del dato arqueológico en el terreno se podrán sortear estas ambigüedades y contrastar, al menos en forma parcial, las fuentes etnohistóricas surgidas de cronistas que estuvieron próximos a la problemática regional aunque sin conocer la zona, así como etnohistoriadores que han escrito sobre ella sin reconocimientos de terreno. Datos éstos que de por si son imprecisos en cuanto a las posiciones geográficas tanto de los establecimientos indígenas -esto sucede en el particular caso de las guarniciones militares, y debe descartarse por inapropiado el término "fortaleza"de Esquile, Lecoya, Escapama, Taraya y Aquilcha, construidas por los Inka para protegerse de las invasiones chiriguanas y mencionadas en las crónicas (Salas 1945, 66. Saignés 1985, 31. Delcourt 2001, 12. Presta 2001, 26. Barragán Vargas; 2001, 58). Algunas de 
ellas son reconocibles, otras, en cambio, son de difícil adscripción a las guarniciones arqueológicamente reconocidas en los trabajos de campo, lo cual ensombrece también la ubicación de las parcialidades e incluso de la toponimia original.

\section{El Sur boliviano y Norte argentino: desde los Andes a las Yungas}

La cordillera de los Andes Orientales alcanza hasta casi 6.000 m.s.n.m. en el actual territorio de Bolivia. Posee un sentido general N-S y transcurre por los actuales departamentos de La Paz, Cochabamba, Potosí, Oruro, Chuquisaca y Tarija. Es conocida también como Cordillera Central y transcurre diversificada en cordones semiparalelos que se abren en forma de abanico hacia el S. Estos cordones reciben diferentes topónimos, de acuerdo a su situación geográfica, entre ellos Cordillera de los Azanaques, Chocaya, San Vicente, Central, de Los Frailes, de Los Chichas, de Lipez (Muñóz Reyes 1980). En su continuidad meridional penetra en territorio argentino, en las actuales provincias de Jujuy y Salta, y es conocida como Cordillera o Sierra de Santa Victoria.

Intercalados entre estos cordones serranos se inscriben una serie de valles intermontanos de singular fertilidad para la agricultura. Su traza general es longitudinal NNO a SSE y en la geografía boliviana son conocidos como "valles mesotérmicos", están ubicados entre altitudes que median entre $\operatorname{los} 2000$ y 3000 m.s.n.m. y responden por su similitud ecológica a los valles tipo keshua de la sierra peruana (Pulgar Vidal 1946). Están surcados por ríos de montaña de regular caudal que se incentiva en épocas estivales. Estos pertenecen a la Cuenca del Plata. Entre ellos se destacan los ríos San Juan Mayo u Oro, Tupiza, Cotagaita, Grande de Tarija y Pilaya en Bolivia. En territorio argentino corresponden los de Santa Victoria, Nazareno, Iruya, El Pescado y San Francisco. Todos derivan sus aguas a las cuencas del Pilcomayo y del Bermejo y, luego al río Paraguay. Otros cauces menores se activan en épocas estivales confluyendo sus aguas sobre los nombrados, entre ellos se encuentra el Arroyo Ñoquera, que corre con ligereza por un estrecho y ríspido cañadón a una altura superior a los 3400 m.s.n.m., derivando sus aguas al San Juan Oro.

Estos altos parajes de los Andes Orientales reciben una considerable cantidad de bautismos regionales que enriquecen la toponimia -en mayor medida aborigen, en lengua aymara y kechua-, pero conducen a confusiones para quienes no los han recorrido en el propio terreno. Los sitios que mencionaremos en este informe se encuentran situados entre las montañas, sus pie de montes y fondos de valle, entre las cuencas de Tarija y Tupiza y que los lugareños, e incluso algunos mapas del Instituto Geográfico Militar de Bolivia (Hojas SF 20-1 y 20-5. Serie H531. E. 1:250.000), identifican como sierras de Yunchará, Tajzara o Tarachaca (donde chaca significa puente [K]) y Mochará, las que alcanzan alturas superiores a los $4600 \mathrm{msnm}$ y forman parte de este sistema montañoso.

Hacia el levante este paisaje cae en altitud con pendientes abruptas dando lugar a las yungas o también conocidos como los pie de montes orientales que se extienden sobre latitudes inferiores a $\operatorname{los} 64^{\circ} \mathrm{O}$. de Greenwich y entre los 2.000 y 1.000 metros cubiertos de bosques bajos y espinosos y luego las tierras bajas del Gran Chaco, por debajo de los $1.000 \mathrm{~m}$. y tapizadas por un bosque cerrado y húmedo. 
Territorios ocupados que fueron llamados "los pueblos del Este" y que desde la óptica Inka primero, y española después, se identificaban como los Antis o los Moxos de filogenia Arawak o Tupí-Guaraní. Hacia el sur de las cuencas del Pilcomayo-Bermejo se localizaba un intrincado mosaico de etnias conocido como Wichis o Matacos, Guaycurú, Vilelas, Tobas, Chané y fundamentalmente los belicosos chiriguanos.

\section{La ocupación humana en tiempos del Tawantinsuyu}

Desde el punto de vista histórico y arqueológico el topónimo que mejor les cabe a las regiones "del alto" -esta designación incluye al altiplano y a los valles mesotérmicos del sur boliviano- es el de Cordillera de Los Chichas. Fue este pueblo indígena el más populoso de tiempos protohistóricos y el dueño natural de esas montañas, de sus valles, pasturas y sementeras. Una formación social de tipo señorío muy probablemente segmentada en diversas parcialidades alojadas en los valles de las actuales provincias potosinas de Nord y Sudchichas y en las tarijeñas de Aviléz, Arce, Mendez y Cercado cuya existencia ha sido documentada histórica y arqueológicamente (Salas 1945, Espinoza Soriano 1969, Raffino 1993).

Estos territorios guardan numerosas trazas de ocupación indígena prehispánica, especialmente del período de Desarrollos Regionales o Intermedio Tardío pre-Inka, correspondientes al periodo abarcado entre los siglos IX a XV. También de la cultura preinkaica de Tarija definida por J. Arellano López (1984). En cambio no hemos reconocido ningún rasgo arquitectónico o artefactual que testimonie influencias Tiwanako, sólo tiestos aislados con reminiscencias Tiwanakotas final y Mollo, hallazgos oportunamente señalados por J. Arellano López (1984: 77).

Numerosas trazas de instalaciones originadas durante el Intermedio Tardío son reconocibles en el altiplano de Tajsara, Ñoquera, Pozuelos, Palqui, Kiskacancha, Curqui y Sama. También y con mayor énfasis en el interior de los valles longitudinales de tipo keshua: Talina, Tupiza, Suipacha, Cotagaita, San Juan Mayo y el grupo de valles interconectados de Tarija-Padcaya-Camacho-Antigal. Algunas derivaciones meridionales ocuparon las regiones de Nazareno, Santa Victoria Oeste, Iruya y Vallegrande en el extremo norte de Argentina; sitios Titiconte, Arcayo, Zapallar, San Pedro, Rodeo Colorado y Nazareno, junto a las guarniciones de Puerta de Zenta, Cerro Amarillo, Pueblito Calilegua, Cerro Chasquillas y Chasquillas Tampu entre otros (Debenedetti y Casanova 1935, Márquez Miranda 1939, Raffino 1991: 221 y 1993: 213).

El poblamiento de estos territorios en tiempos anteriores al Tawantinsuyu correspondió a las jefaturas Chichas por el norte y Omaguaca por el sur. Los Chichas junto a los Caracara, los Charcas y Chuis fueron: “...soldados desde el tiempo de los ingas llamados Inga Yupangue y Topa Inga Yupangue y Guaynacava y Guascar Inga y cuando los españoles entraron en esta tierra los hallaron en esta posesión... reservados de pechos y alcavalas y de todas las demás tasas y servicios personales que se entiende de guarda de ganados y de ser ovejeros y de hacer la mita en la corte de la gran ciudad del Cuzco y de ser canteros, tejedores de la ropa de cumbe y de abasca y de ser chacareros, albañiles 
y canteros gente que tenía por costumbre trasponer un cerro a otra parte a puras manos y labranzas como se hacía en el tiempo de los ingas por otras generaciones como es público y notorio..." (Memorial de Charcas; [1582] En: Espinoza Soriano 1969: 24).

Esta atribución sobre la aptitud de los Chichas como maestros albañiles y canteros se comprueba en las instalaciones arraigadas en el foco de sus territorios. En las quebradas de Talina, Suipacha, Tupiza, Cotagaita, Ascande y otros valles de las actuales provincias de Nord y Sudchichas. A la vez se comprueba que esta tradición de grandes albañiles persistió durante la colonia y se encuentra señalada con mayor precisión témporo-espacial por A. M. Presta (2001: 34), quien sobre fuentes puntuales rescata la importancia de los Chichas en la fundación de Tarija: 140 indios de esta parcialidad bajo el estatus de tendarunas fueron utilizados en la construcción de casas, fuertes, acequias y trazado de calles.

Estas son las naciones más reconocidas tanto por su número de habitantes como por los territorios que ocupaban. Pero, junto a ellas, los datos mencionan un mosaico de parcialidades menores en cuanto a su número y más difíciles de identificar territorialmente, entre ellos los Charangas, Churumatas, Erquis, Tomatas, Juríes, Coimatas y Ocloyas.

La contraparte étnica de estos grupos andinos se halla en las regiones boscosas y de las yungas del gran Chaco, poblados en esos mismos tiempos por formaciones tribales del tronco Arawak o Guaraní, asignaciones éstas muy genéricas que involucran decenas de entidades de estructura social tribal en términos de E. Service (1971), entre las cuales y desde la óptica trazada desde el Cuzco Inka, sobresalen los temibles chiriguanos, que asolaron con sus invasiones la frontera oriental de esta región del Tawantinsuyu primero, y las poblaciones españolas más tarde.

\section{Vestigios Inka entre Tupiza y Tarija}

“...llegado (Huayna Cápac) al Collao pidió cuenta de los tributos. Entró en la laguna Titcaca, é hiço sacrificios en Chuquiabo. Mandó, que entendiesen muchos Indios en sacar Oro, y que en los (...) Chichas, se sacase Plata, i llevase al Cuzco. Trasplantó Mitimaes de unas Provincias á otras, que es mudar las Guarniciones (...) Mandó edificar Tambos, i Plaças, dando él la traça, limitando los terminos de muchas Provincias (...) Embió sus Capitanes contra los Chiriguanaes, pero volvieron huiendo..." (Herrera y Tordesillas, 1736, Década V, Libro III, Cap. XVI, 77-79)

El registro arqueológico reconocido durante nuestras misiones arqueológicas en la región meridional de Bolivia comprende varios tramos de capacñam de factura Inka, una serie de establecimientos con arquitectura de superficie que sirvieron de apoyo al tendido de la red caminera (tampus), dos centros administrativos de alta complejidad (Oma Porco y Chuquiago de Suipacha), explotaciones agrícolas en terrazas (Tulkumarca, Camacho), corrales agrupados y un par de puentes de piedra, uno de ellos de extraordinaria factura 
levantado sobre el río Ñoquera en la Provincia de Aviléz, Departamento de Tarija. En estos establecimientos la elaboración es visible gracias a la conjunción de los rasgos arquitectónicos clásicos del imperio Inka con otros que se muestran como típicos de la arquitectura Chicha regional.

A estas evidencias Inka se suman una serie de instalaciones preInka de indudable génesis Chicha y reductos de construcción más rústica de probable factura en tiempos históricos, que creemos fueron construidos por las poblaciones locales luego de la caída del imperio Inka para proteger la frontera de los avances chiriguanos. Se trata de pequeños abrigos defensivos construidos en la cima de cerros con pequeños atisbos de arquitectura militar y cuya génesis parece corresponder a la segunda mitad del siglo XVI y XVII.

\section{A. Chuquiago-Villa Victoria-Charaja-Supira-Livi Livi-Ñoquera-Sama-Tajzara- Calderillas-Abra del Inka-Eı Mesón-Pinos-Bella Vista-Tolomosa.}

Forma parte del Capacñam que originalmente unía el centro administrativo Inka de Chuquiago en el Valle de Suipacha (Potosí) con Tarija. Los tramos relevados se inician en Chuquiago, un gran sitio Inka reconocido por nosotros en 1984 situado sobre los $21^{\circ}$ 34' S., 65 38' O.; 2.960 m.s.n.m. (Raffino 1986 y 1993). Este es el capacñam principal que proviene del Cuzco, Rajchi, Hatumcolla, Chucuito, Desagüadero, Andamarca, Oma Porco, Aullagas y Tupiza hasta llegar a Chuquiago del Valle de Suipacha.

En este último sitio, un verdadero tinkuy donde los inkas explotaban el oro y seguramente un centro administrativo por la calidad arquitectónica, el capacñam se divide en dos. El ramal principal continúa en dirección al NO argentino mientras que otro ramal se desvía hacia el levante y luego transcurre por el tampu de Villa Victoria $\left(21^{\circ} 35^{\prime} \mathrm{S} .65^{\circ}\right.$ $36^{\prime}$ O.) y torciendo hacia el E. el Pukará de Charaja ( $\left(21^{\circ} 35^{\prime} \mathrm{S} .65^{\circ} 34^{\prime} \mathrm{O}\right.$.) Charaja ha sido una guarnición destinada a proteger el capacñan, que en ese punto continúa por un estrecho cañadón con rumbo a Supira, y se levanta en la serranía que domina el amplio codo que produce en ese lugar el río, inmediatamente por encima del camino del Inka. Contiene varias murallas defensivas intermitentes y un puñado de recintos de planta rectangular de factura Chicha que no llegan a conformar la imagen arquitectónica de las kanchas, aunque en su superficie aparecen fragmentos de alfarería Inka provincial.

Desde este último establecimiento Inka-Chicha el camino fue reconocido a través de sucesivos segmentos intermitentes. Asciende por las montañas hacia el E. en dirección a Supira, Piedra Blanca, Livi Livi y hacia el río San Juan Oro. El rumbo de este último ha trazado una amplia curva torciendo primero hacia el S., y luego hacia el E. y sirve de límite entre los departamentos de Potosí y Tarija.

En estos parajes hemos encontrado dos tambos Inka (Livi Livi I, Livi Livi II), varios segmentos del capacñam dispuestos en cornisa sobre el faldeo de los cerros y una apacheta Inka próxima al paraje Piedra Blanca que sirve como mojón en una divisoria de aguas. Estos conjuntos están situados entre los 2.500 y 3.500 metros de altitud. 
Una vez transpuesto el río San Juan Oro y ya en territorio de Tarija, se arriba al paraje de Noquera donde registramos un amplio tambo y un excelente puente de piedra. Ambos de neta factura Inka. El tambo de Ñoquera ha sido lamentablemente perturbado por la construcción de una moderna escuela y puesto sanitario que ha utilizado la piedra de los paramentos antiguos. Aún así se conserva un sector con cierta originalidad Inka, conformado por construcciones tipo cancha o RPC y un amplio espacio nivelado artificialmente que pudo corresponder a construcciones de aukaipata y quizás un par de kallankas.

En cuanto al puente Ñoquera es un clásico Rumichaca (rumichaca; rumi = piedra; chaca $=$ puente K), construido en la posición meridiana $21^{\circ} 37^{\prime}$ S. y $65^{\circ} 08^{\prime}$ O. y a 3.444 $\mathrm{m}$. de altitud. Las imágenes que acompañan esta descripción expresan la solidez y el megalitismo del puente, los cuales explican su perdurabilidad ante el paso de más de cinco siglos desde su construcción. Se realizó con un doble muro de grandes bloques poliédricos semicanteados, los que fueron cuidadosamente ensamblados y fijados con barro y ripio. Los dos extremos del puente se incrustan en los faldeos de los cerros, tornando innecesaria la construcción de estribos de apoyo. Por lo demás, es inmejorable la verticalidad de sus muros laterales. Gruesos tirantes de madera, tendidos horizontalmente, se alternan entre los muros. Fueron deliberadamente colocados para darle elasticidad a la masa pétrea

El rumichaca de Noquera tiene un rumbo NE-SO, $15 \mathrm{~m}$. de largo y 2,80 m. de ancho en su base; su altura por sobre el nivel del cauce es de $8 \mathrm{~m}$. y el ancho de la calzada es de 2,10 m. La alcantarilla de su fondo es de forma trapezoidal con una abertura de 1,40 $\mathrm{m}$. de alto, $0,70 \mathrm{~m}$. de ancho en su parte superior y $0,80 \mathrm{~m}$. en la inferior. Un grueso dintel formado por seis bloques corona la alcantarilla, mientras que el otro extremo, el de la calzada, fue terminado con un empedrado de bloques planos de mayor tamaño.

El tiempo transcurrido y la propia utilización del puente hasta la actualidad para el tránsito de hombres y animales (llamas, caballos, mulas y burros) están probados por la persistencia de restos visibles y aún en funcionamiento del capacñam en ambos laterales del puente. Uno de estos ramales conduce directamente al tambo Inka de Ñoquera, situado a unos $500 \mathrm{~m}$. al E. y en el que sobreviven un par de RPC. Este establecimiento Inka ha sido evidentemente mucho más grande que lo que sobrevive hoy día bajo las modernas construcciones del pueblo de Ñoquera. Una extensa superficie plana situada entre las construcciones Inka y las modernas, nos sugiere la existencia de una antigua plaza Inka (aukaipata, K), perturbada por un cementerio y una escuela levantada hace muy pocos años.

El ramal opuesto del capacñam conduce en dirección al río San Juan Oro y en dirección al valle de Tupiza por los restos Inka ya mencionados: los tramos de capacñam en Piedra Blanca y Supira, los tambos de Livi Livi y Villa Victoria, la guarnición de Charaja y el centro administrativo de Chuquiago.

La estrechez de la calzada del puente de Ñoquera -2,10 m.-, no ha permitido el tráfico de los carros introducidos por los españoles, lo cual ha contribuido a la conservación del puente en estado original. Asimismo se infiere que los ingenieros que lo planearon y 
los albañiles y canteros que lo construyeron conocían muy bien su oficio. La utilización de troncos de madera intercalados entre los bloques pétreos para quitarle rigidez y evitar que la superestructura se quebrara y desmoronara por causas sísmicas-típicas de la región andina- es una tangible muestra de aplicación de "tecnología de punta" en materia de obras hidráulicas. Los muros laterales y la propia alcantarilla se conservan admirablemente; ocurre lo mismo con los extremos del puente, los cuales, sin embargo, comienzan a desnudarse por la natural degradación de los cerros en los que se apoyan.

Volviendo a la traza del capacñam entre Tupiza y Tarija vale decir que desde Ñoquera hacia el E. el rumbo prosigue hacia Curqui ( $21^{\circ} 29^{\prime}$ S., $65^{\circ} 04^{\prime}$ O.), pasa al S. del Pucará de Condorhuasi (21 $28^{\circ}$ S. , $65^{\circ}, 02^{\prime}$ O.). “...El Inga, cuando era señor desta tierra, tenía aqui guarnición de gente de guerra contra estos Chiriguanaes, los cuales, entrando los nuestros, en este reino, la dejaron y se volvieron a sus tierras..." (Lizárraga 1999, Cap. CVIII, 196). Esta guarnición fue mencionada por el geógrafo O. Schmieder (1924) y antes de nuestro reconocimiento fue visitada por V. Lee $(1992,40)$ quien levanta un croquis del sitio.

En efecto Condorhuasi es una típica guarnición construida para proteger el capacñam que combina arquitectura Inka con Chicha. Se levanta sobre una meseta a 4.000 m. de altitud desde donde se domina el paisaje hacia Ñoquera y el río San Juan Oro por el poniente y hacia la frontera chiriguana por el levante. El pucará es muy similar en su técnica constructiva a la instalación Inka-Chicha de Titiconte de Iruya (R. Raffino et al. 1986, 63 y 1988, 206, Raffino 1993, 214). Está compuesto por una larga muralla semiperimetral de un kilómetro de extensión y unos $2 \mathrm{~m}$. de altura, provista de cinco puertas y algunas troneras que protege el establecimiento por el oeste. Sobre este mismo sector aparece una segunda muralla más baja y de medio kilómetro de extensión. El resto del perímetro (sectores N., E. y S.) está protegido por barrancos y peñones naturales. En el interior se levantan unos 100 conjuntos de recintos residenciales y probablemente algunas collcas que expresan arquitectura Inka de kanchas con muros interiores con hornacinas y vanos trapezoidales.

El estilo arquitectónico es mixto, advirtiéndose las estructuras Chicha por la presencia de recintos iguales asociados sin formar estructuras tipo Kancha, paramentos de piedra seleccionada provistos de vanos rectangulares coronados con dinteles y peldaños en saledizo. El conjunto fue levantado con piedra seca.

Compartimos la opinión de Lee (1992: 18) en cuanto a que los Inka probablemente reocuparon un reducto defensivo local pre-existente-nosotros creemos que fue originalmente levantado por los Chicha- para construir esta guarnición, imponiendo su propia arquitectura.

Prosiguiendo con el derrotero, el camino Inka asciende en cornisa por Pamparayo. En este último lugar, una apacheta doble indica el cambio de dirección de las pendientes. Desde este punto, de manera intermitente, se han localizado segmentos en dirección a la cuesta de Sama, donde hemos hallado vestigios de un segundo puente de piedra, originalmente Inka, pero reconstruido en tiempos históricos.

La Apacheta Inka Pamparayo (4.100 m. 21 $30^{\prime}$ S., $65^{\circ} 01^{\prime}$ O.) marca uno de los puntos de mayor altitud por donde transcurre el camino. De modo que los Inka, siguiendo 
su clásica estrategia caminera, marcaron con esa construcción la altitud máxima y el cambio de pendiente. Desde allí desciende en dirección al valle de Tarija pasando por los parajes de Sama a $3.700 \mathrm{~m}$. ( $21^{\circ} 29^{\prime} \mathrm{S}$., $65^{\circ} 53^{\prime} \mathrm{O}$.) y en forma más abrupta el descenso del capacñam conduce hacia la Apacheta de Tucumilla ( $21^{\circ} 28^{\prime}$ S., $65^{\circ} 52^{\prime}$ O. $)$ a $3.470 \mathrm{~m}$. y a Pueblo Viejo. Desde este punto hay una bifurcación de caminos en dirección a Solá y a Marquiri. Estos tramos de caminos han sido frecuentemente utilizados desde tiempos históricos hasta la actualidad para descender al valle de Tarija, cruzado por los ríos San Lorenzo y Guadalquivir. Esta circunstancia ha determinado sucesivas remodelaciones, por lo que no podemos asegurar si fueron originalmente Inkaicos.

Sobre la latitud $21^{\circ} 29^{\prime} \mathrm{S}$. y $64^{\circ} 53^{\prime} \mathrm{O}$. se levanta la segunda obra de infraestructura vial de relevancia en este derrotero de comunicaciones entre la puna y los valles mesotérmicos. El rumichaca de Sama está emplazado a $3.660 \mathrm{msnm}$. Su largo varía desde los 22 metros, sobre el camino, a 12 metros en su base. El ancho de la calzada es de 5.7 metros y posee muros de contención a los lados de 1 y $0.80 \mathrm{~m}$. de ancho respectivamente. La altura máxima es de 2 metros; posee 3 alcantarillas o aberturas de escurrimiento de forma trapezoidal de $0,50 \mathrm{~m}$. aproximadamente y $0,80 \mathrm{~m}$. de alto de un lado y $2 \mathrm{~m}$. del otro. Posiblemente la tercera alcantarilla esté sepultada por los sedimentos o dos alcantarillas confluyan en una sola.

La técnica constructiva del puente de Sama no es tan cuidada como en el puente de Ñoquera. El aparejo murario es rústico, grandes rocas poliédricas semicanteadas se superponen unas sobre otras sin fijación de mortero y sin un orden aparente salvo las columnas e interior de las alcantarillas. La obra fue levantada en dos momentos diacrónicos. El más antiguo tiene componentes arquitectónicos Inka, como las alcantarillas trapezoidales y la base del puente. Sobre esta fundación inicial se advierte un serio intento de ensanchamiento de la calzada para aumentar su anchura y facilitar el tránsito de carros; lo cual significa que este segundo momento recala en tiempos claramente históricos.

Otro ramal de capacñam se bifurca hacia el S. en dirección a «El Pasaje» de «Laguna Tajzara» $\left(21^{\circ} 44^{\prime}\right.$ S., $65^{\circ}$ 02' O., $3.750 \mathrm{~m}$.) donde se hallaron dos nuevos tampus Inka: Tajzara Alto con varios conjuntos de kanchas residenciales y Paraje Tajzara con 34 corrales agrupados y alineados que los Inka construyeron para encerrar llamas. Estos establecimientos fueron programados y construidos para apoyar el tráfico desde el altiplano de Chuquiago y Ñoquera hacia Tarija por el camino de La Patanka que pasa entre ellos.

Desde este último tambo comienza un pequeño ascenso a la serranía de Tajzara y luego el descenso hacia Calderillas donde reconocimos otro tambo Inka. Transpuesto este_sector se produce la abrupta caída hacia el Valle de Tarija. Por espacio de unos 10 kilómetros (10 horas de marcha) se suceden largos tramos de capacñam de excelente factura del tipo "en cornisa, empedrado con muro de contención y desagüe" (Raffino 1981, 204) o de "Retention Walls" (Hyslop 1984, 242).

El capacñam se encuentra magníficamente empedrado y posee desagües subterráneos y muros de contención. Definitivamente son los mejores exponentes construidos por el Tawantinsuyu al S. de Cochabamba. Solamente comparables con los tramos hallados en 
Vallegrande (Jujuy) y Quebrada del Toro (Salta) (Raffino 1993). Los siguientes puntos con tambos con arquitectura Inka responden a los topónimos de Calderillas ( $21^{\circ} 44^{\prime}, 64^{\circ} 57^{\prime}$ , 3.100 m.) Abra del Inga (2.930 m.) y El Mesón (2.444 m. de altitud). El descenso desde Abra del Inga hasta El Mesón es abrupto y transcurre en medio de un paisaje de singular belleza. Desde este sitio el capacñam se pierde bajo las construcciones modernas en las cercanías de Pinos en dirección a las modernas localidades de Bella Vista y Tolomosa.

Este ramal de capacñam es conocido como el camino de la Patanka y fue históricamente atribuido a las jefaturas Chicha. Es probable que la construcción original haya respondido a estas formaciones locales, sin embargo el tipo de arquitectura, la conexión directa con centros administrativos (Chuquiago de Suipacha), con los tampus, con kanchas (RPC), collcas, apachetas, corrales y dos puentes de piedra, junto a la cerámica hallada a lo largo de su trayecto, no dejan ninguna duda que su reconstrucción o remodelación responde al horizonte Inka. Este camino cubre aproximadamente una distancia de quince leguas españolas ( 1 legua $=6 \mathrm{~km}$.) siendo coincidente con la que, de acuerdo al relato de Fray Lizárraga, separa Talina de Tarija. Desde Chuquiago a El Mesón, el trayecto podría ser recorrido a lomo de mula en tres días.

Si la expedición de Pedro de Candia y Diego de Rojas aplicó una estrategia similar a la de Diego de Almagro en su entrada al Norte argentino y Chile. Es decir, siguiendo el capacñam Inka, usando guías cuzqueños y utilizando los tambos de apoyo, no nos quedan dudas que el camino Chuquiago, Livi Livi, Ñoquera, Tajsara, La Patanka y Tolomosa, fue la ruta seguida por los españoles en su primer entrada a Tarija de 1539.

A escasa distancia hacia el N. del tambo de Ñoquera y por encima del tramo de camino en el río San Juan Oro una vez transpuesto Chuquiago del valle de Suipacha, los pucarás de Charaja y Condorhuasi son dos clásicas guarniciones militares con componentes arquitectónicos y alfarería Inka y Chicha. En ambos casos es probable que se trate de sitios multicomponentes, es decir fundados antes de la invasión Inka y luego ocupados y remodelados por el Tawantinsuyu, el cual impuso la arquitectura militar defensiva con el implante de murallas perimetrales, troneras, balcones, torreones y otros elementos oportunamente clasificados por nosotros (Raffino 1991, 123).

Tanto en Charaja como en Condorhuasi la selección del espacio fue cuidadosamente planeada para asegurar protección en apoyo del capacñam que conectaba las quebradas de Talina, Suipacha y Tupiza con Tarija. En otras palabras, la ruta entre el altiplano minero de Potosí con las Yungas bolivianas.

Es probable que otro tramo de camino Inka reconocido en la región de Orozas, El Saire, El Baisal y Tariquia (indicado en la sección D de este aporte), sea la prolongación hacia el levante de este camino, un importante segmento que desde la región de Tarija se internaba en las yungas del oriente boliviano trasponiendo el meridiano de $64^{\circ}$ Longitud. Oeste.

Continuando el derrotero en dirección al valle grande de Tarija se registra el segundo puente, situado en la región pedemontana que baja desde Sama al valle. A diferencia del de Ñoquera, aquí la original fundación Inka sufrió una remodelación en tiempos históricos. Se 
encuentra sobre el faldeo oriental de un cerro de fuerte pendiente, a $3.700 \mathrm{~m}$. ( $\left(21^{\circ} 29^{\prime} \mathrm{S}\right.$., $65^{\circ} 53^{\prime} \mathrm{O}$.). Fue íntegramente construido en piedra (rumichaca) y sus medidas son $22 \mathrm{~m}$. de largo de su área de pasaje por $12 \mathrm{~m}$. en su base. Posee tres alcantarillas trapezoidales de clásica factura Inka en su base, para favorecer el pasaje del agua en una ladera con pendiente promedio de $30 \%$. El pasaje superior del puente fue tapizado con grandes piedras planas, ensanchado hasta los 5,70 m .para suplantar el original tránsito de caravanas de llamas Inka por caballos, mulas, burros e inclusive carruajes. En este sector se puede observar que la construcción, originalmente de estilo Inka, fue modificada en tiempos históricos.

\section{B. Capacñam entre el altiplano y los valles meridionales de Tarija: Copacabana- Torohuaico-Campanario-Chasquiwasi-Camacho}

Es otro ramal de excelente construcción que comunica el altiplano del actual poblado de Copacabana, situado al S. de las lagunas de Tajsara, con el valle de Camacho. Sus primeros remanentes aparecen en Torohuaico y el Cerro Campanario $\left(21^{\circ} 52^{\prime} \mathrm{S} ., 6^{\circ} 0^{\prime} \mathrm{O}\right.$.)

Una apacheta Inka de 2 metros de alto, construida a $4.280 \mathrm{~m}$. de altitud, marca el cambio de pendiente de la serranía que separa la puna de Tajsara y el inicio del descenso hacia al oriente, en dirección al Valle de Camacho. El camino se extiende por espacio de 8 a 10 kilómetros desde $21^{\circ} 52^{\prime}$ S., $65^{\circ} 0^{\prime}$ O. hasta $21^{\circ} 53^{\prime}$ S., $64^{\circ} 56^{\prime}$ O. Fue construido en cornisa siguiendo las irregularidades de la montaña y con muros a la manera de refuerzos basales en su mayor parte. Posee largos tramos empedrados y puede ser transitado en su totalidad entre Cerro Campanario y el Valle del Río Camacho. El trayecto entre ambas localidades insume unas 10 horas de marcha.

A dos horas de marcha descendiendo desde la Apacheta Campanario se hallan los restos de un pequeño tambo Inka, sus muros yacen debajo de corrales actuales que han reutilizado las pircas originales. Este tambo marca la bifurcación del capacñam en dos ramales. El original continúa su descenso hacia el río Camacho, pasando por agudas pendientes a un par de centenares de metros por sobre el fondo de la quebrada. Este ramal fue el elegido para continuar nuestra marcha y fue seguido por espacio de 8 horas hasta que, ya en el fondo de valle, se pierde sobre las modernas construcciones y granjas antes de llegar a la altura del pueblo Camacho ( $21^{\circ} 53^{\prime}$ S., 64 56 $56^{\prime}$ O.; $2.400 \mathrm{~m}$. de altitud).

El implante de construcciones y campos agrícolas modernos ha perturbado las trazas Inka de Camacho, sepultando numerosas construcciones de piedra hoy día apenas visibles, así como también algunos cimientos de recintos de planta circular-probablemente antiguas collcas- $y$ terrazas de cultivo.

Queda pendiente la investigación sobre el restante ramal del camino para establecer si se trata de un camino Inka. Nosotros creemos que se trata de un camino histórico. Por el momento se advierte que se desvía hacia el S., tomando el rumbo en dirección a las localidades de La Huerta y Rejara, y desde allí hacia Sococha o, alternativamente, hacia Mecoya en los límites actuales entre Bolivia y Argentina, y a Santa Victoria en el extremo boreal de la Provincia de Salta. 


\section{Capacñam Tullkumarka-Misca-Pinos}

Tullkumarka es un sitio multicomponente situado en el valle de Antigal $\left(21^{\circ}\right.$ $49^{\prime}$ S., $64^{\circ} 55^{\prime}$ O., $2300 \mathrm{~m}$ de altitud). La sección arqueológica actualmente ocupa unas 100 hectáreas a ambos lados de una quebrada donde la arquitectura de varios conjuntos de RPC se combina con posibles collcas rectangulares, terrazas agrícolas y arquitectura local preexistente. La técnica constructiva evidencia la presencia de paredes dobles de piedra rellenas con ripio. Las ruinas de Tullkumarka fueron descriptas brevemente por A. Posnansky (1945) y recientemente por P. Delcourt (2001) quien obtuvo un fechado de radiocarbono de $1430 \pm 45(440 \pm 50 \mathrm{BP})$.

Aunque es probable que su filiación sea anterior a la invasión del Tawantinsuyu, Tullkumarka ha sido un hito importante en la construcción del capacñam debido a la fertilidad de su valle. El camino que articula con el sistema vial Inka desciende por la serranía de Tajzara y después transcurre por el O. de Tullkumarka, descendiendo hasta el fondo del valle, casi $1 \mathrm{~km}$. al $\mathrm{O}$, donde son visibles nuevos segmentos $\left(21^{\circ} 48^{\prime} \mathrm{S}\right.$., $64^{\circ}$ 54' O., $2.220 \mathrm{~m}$. de altitud).

En este último punto el camino asciende otra vez y tuerce hacia el NE hacia los valles de Misca y Pinos. Este segmento tiene una longitud de aproximadamente cinco kilómetros y puede ser recorrido fácilmente en una hora. Su mayor parte fue construido en cornisa con bases reforzadas y encerrado entre muros pero sin alcanzar la calidad arquitectónica del de La Patanka. Este ramal corre conectando los valles de Tullkumarka-Antigal y Misca. En su tramo medio ( $21^{\circ} 48^{\prime}$ S., $64^{\circ} 53^{\prime}$ O.) hemos registrado un pequeño puente-alcantarilla de piedra con albañilería similar al de Ñoquera, aunque mucho más pequeño. La estructura parece haber sido mantenida en uso hasta la actualidad por lo que se halla bien preservada a pesar que los derrumbes han sepultado parte del muro que da sobre la sierra.

Finalmente, en las proximidades del valle de Misca, el capacñam desciende desde el faldeo de la sierra hacia el fondo de valle y, como sucede en otros territorios habitados, se pierde bajo las modernas construcciones.

\section{Capacñam entre la región de Padcaya-Tarija y las Yungas orientales: El Saire- Orosas-Chorro-Tariquia}

Examinamos este ramal del capacñam en el S. de la actual localidad de Padcaya con su trazado dirigiéndose hacia el levante. Los primeros vestigios aparecen cerca de Chasquiwasi, donde restos de pavimento de finas piedras planas están preservados. El camino es claramente reconocible en el moderno cementerio de El Saire (donde piedras del capacñam fueron usadas en las lápidas de tumbas históricas); luego en dirección al E. en el tampu de El Saire y en el sitio Chicha-Inka de El Saire II. Siempre con rumbo al E., el camino conecta los puntos de Orozas bajo, El Chorro, El Angosto y Alisos del Carmen, trasponiendo después la serranía para descender hacia el piedemonte boscoso de Tariquia, en la Provincia de Arce, donde alcanza un alto grado constructivo en el lugar llamado La Escalera, con una piedra y pavimento escalonado de calificada ejecución. Desde ese punto 
el capacñam se interna en la espesura del bosque espinoso propio de las yungas orientales que impide una aceptable visibilidad arqueológica.

Futuros trabajos de campo deberán corroborar si esta sección del capacñam es la continuación del de La Patanka (ramal A), o de Torohuaico-Campanario (ramal B). Queda claro que, en ambos casos, desciende desde el altiplano donde los Inka construyeron los grandes establecimientos de Chuquiago, Ñoquera (puente y tambo), Livi Livi y Tajzara, a la vez que los tambos, apachetas, enclaves agrícolas y depósitos, para concretar una ocupación territorial bien sostenida entre la Puna los valles mesotérmicos del SE boliviano hasta por lo menos el piedemonte de yungas de Tariquia.

Por el momento la arqueología de campo nos indica que el capacñam se interna en el territorio de los "Anti" ocupados por tribus chiriguanas y dentro del paisaje de bosques, las yungas o las tierras bajas del levante, trasponiendo los $64^{\circ} 28^{\prime}$ O. y los $22^{\circ} \mathrm{S}$. Hasta esos puntos no quedan dudas arqueológicas de ocupación Inka.

\section{Tecnología Inka de punta:}

\section{A. Los rumichaca de Ñoquera y Sama en el repertorio tecnológico del Tawantinsuyu}

Una breve historia sobre los puentes Inka comienza con los primeros conquistadores de Perú, entre ellos el capitán Hernando Pizarro (1533) y sus soldados, Miguel de Estete (1533), Francisco de Xerez (1534), quienes también serían los primeros en ofrecer una descripción de la capital Inka, el Cuzco. Pocos años después la descripción de un puente de piedra, un rumichaca, acaparó la atención del cronista Cieza de León (1551). Esta obra estuvo situada en el paraje Huaca, sobre el río Carchi (Ecuador). A fines del siglo XVI (1596) el inspector de puentes virreinales Espinosa Campos describe un puente de piedra Inka situado en Izochaca (Huánuco) y también varios puentes conservados en Taricay, Chuquipampa, Acoxa y Huánuco Pampa (Mellafé 1965).

Los puentes imperiales tampoco escaparon a la descripción del cronista Garcilaso de La Vega (1613), obras conocidas como "puentes de canasta de mimbre tirados por sogas" (llamados uruyas o tarabitas), también el de tipo "flotante" construido con balsas de juncos y totoras sobre el río Desaguadero en el Lago Titicaca y los magníficos ejemplares de tipo colgante, hechos de fibras vegetales y llamados chaguar, cuyos exponentes más calificados fueron tendidos sobre los rápidos del río Apurimac, en plena sierra peruana. Otro cronista indiano, Guamán Poma (1613) dibuja el puente colgante de Guambuchaca, levantado en la sierra peruana.

En el cuarto meridional del imperio, el Kollasuyu (actual Bolivia, NO argentino, y N. De Chile) son infrecuentes este tipo de obras. Sólo una es mencionada por el cronista franciscano R. Lizárraga ([1595] 1999, Cap. LXXII), el Puente del Inca, levantado sobre el río Camarico en el capacñam que cruza la cordillera andina entre Mendoza y Chile, un puente “...de cuatro varas de ancho...”, estrecho y resbaladizo que: “...para pasar por ella es necesario ir el hombre confesado...". Debe señalarse que el fraile en cuestión había adquirido su experiencia en el tema de los puentes incaicos porque tuvo la oportunidad de 
describir los construidos sobre el río Villcas en Guamanga, el del Valle de Amancay y los puentes flotantes de Cepita y Desaguadero en el Titicaca. Sin embargo, el Puente del Inca en Camarico fue una obra cuya manufactura decepcionó al propio C. Darwin, quien lo conoció en 1835 en su tránsito entre la Argentina y Chile, porque: “...no merecía el nombre de los grandes monarcas que lleva..." (Darwin 1962, 336).

Ya a comienzos del siglo XIX el naturalista prusiano A. von Humboldt les dedica su atención y describe el puente colgante de Penipé, en el Cantón de Guano, en la Provincia de Chimborazo, Ecuador (dibujos de Bouquet) y promediando el mismo siglo, el diplomático norteamericano G. Squier [1863-65] (1974) describe y dibuja a pluma varios puentes explorados entre 1863 y 1865 en la sierra peruana, los de Ollantaytambo, Apurimac, Huatanay y Pampas, utilizados para cruzar los ríos homónimos. El puente colgante hecho de "criznejas" y tendido sobre el caudaloso Apurimac fue sin duda el más extenso (más de $40 \mathrm{~m}$ ) y su fama se vio acrecentada por acaparar la atención de los geógrafos, historiadores y naturalistas decimonónicos más calificados, como el propio Squier, C. Gibson en 1851, C. Markham en 1855 y C. Wiener en 1876. Sobre el epílogo del siglo el naturalista italiano A. Raymondi (1908) se ocupa del puente de piedra que cruza la Quebrada de Chavín de Huantar.

Hacia fines del siglo XIX eran muy pocos los puentes que habían sobrevivido al paso del tiempo, a las destrucciones ocasionadas durante las guerras civiles, a las rebeliones indígenas frente al poder español y a las guerras de la independencia americana. A comienzos de la década de 1970 en territorio peruano sobrevivían alrededor de 80 (D. Gade, 1972). Entre los que quedaron en pie pueden mencionarse el trazado sobre el río Marañón en su desembocadura sobre la Laguna de Lauricocha, en Huanuco, y el de Carabaya. Unos años antes, en 1943, un aluvión había quebrado el de Chavín de Huantar en el Callejón de Huaylas, en Ancash.

Le corresponden al ingeniero peruano A. Regal los aportes más sistemáticos, realizados entre 1936 y 1972, sobre los antiguos puentes construidos por el Tawantinsuyu. Su clasificación, aún vigente, considera cinco tipos de puentes inca en base a la materia usada en su construcción (Regal, 1936, 25), a saber: 1. de troncos y palos ("de consola" o sauchaca [Ay]); 2. de piedra (rumichaca $\mathrm{K}) ; 3$. huaros, oroyas y tarabitas; 4. colgantes; 5. flotantes (huатри [Ay]). El puente hallado en Noquera se inscribe en el segundo tipo.

Como muchos otros rasgos de su arquitectura monumental es muy probable que la antigüedad de los puentes andinos sea muy superior al nacimiento del Tawantinsuyu. Una impresión similar nos deparan otras grandes obras de ingeniería hidráulica, como los acueductos, las represas y los canales subterráneos, cuyo origen puede remontarse a los finales del Horizonte Temprano y al Período Intermedio Temprano (200 a.C.-200 d.C.) y sus manifestaciones enroladas en entidades culturales como Chavín de Huantar y Nazca en la costa y sierra peruanas. En los años 40 el decano de los arqueólogos peruanos, J. C. Tello lanzó esta idea al referirse al puente de Chavín. Similar reflexión se impone J. Hyslop en el capítulo dedicado a los puentes inka en su obra sobre el sistema vial (Hyslop 1992).

Es imposible no imaginar que los grandes estados preincaicos de Huari y Tiwanaku (500-1000 d.C.), que ocuparon el mismo espacio físico que sería conquistado siglos después 
por el Tawantinsuyu, y responsables de la creación de innumerables obras arquitectónicas de real magnitud como sus grandes capitales homónimas, andenerías, caminos, chullpas funerarias, acueductos, grandes depósitos y los magníficos templos, como el Kalasasaya de Tiwanaku, no hayan desarrollado la tecnología apropiada para construir puentes. Es incluso muy probable que esas obras construidas en tiempos preincaicos hayan sido ampliadas y perfeccionadas por el Tawantinsuyu.

Es evidente que los puentes de Ñoquera y Sama fueron obras de infraestructura construidas especialmente para agilizar el tránsito de las caravanas entre Tarija hacia el altiplano de Tupiza y Potosí. Allí los Inka tuvieron importantes explotaciones de oro y plata en Porco y Chuquiago. Explotaciones que fueron continuadas en tiempos históricos. Esta circunstancia se comprueba por las remodelaciones del puente de Sama, una obra que sufrió un replanteo de la cantería y estructura original realizado para que por él puedan transcurrir caravanas de mulas y caballos europeos. No sabemos en qué momento histórico fue efectuado, pero no quedan dudas que el ensanche del puente facilitó también el tránsito de rodados transportando víveres para abastecer a las poblaciones de mineros.

\section{Desde Potosí a Tarija y las Yungas orientales: algunas generalizaciones empíricas.}

Coordinando datos históricos con arqueológicos puede formularse una suma de generalizaciones empíricas en torno al proceso regional, acerca de las características que adquirió el dominio Inka entre la segunda mitad del siglo XV (reinado de Tupa Inka) hasta la entrada española de Diego de Almagro en Tupiza (1536) y Pedro de Candia (1539) en Tarija. Proceso que desemboca en los primeros tiempos de la ocupación española con las capitulaciones del Virrey Toledo y las fundaciones de Santa Cruz de la Sierra (1557) Tarija (1574), y Concepción del Bermejo (1585).

1- Hemos reconocido segmentos inéditos del llamado «Camino Inka de la Sierra» (Herrera y Tordesillas) y sus tambos y guarniciones de apoyo. Éste es el gran capacñam que parte desde la Aukaipata del Cuzco hacia el SSE y avanza por el altiplano de Rajchi, Hatumcolla, Chucuito, Desagüadero, Andamarca, Oma Porco, Aullagas y Tupiza hasta llegar a Chuquiago del Valle de Suipacha. En este importante centro administrativo, el camino se divide en dos ramales.

Uno de ellos es el camino principal, la ruta de Almagro, investigada por nosotros en anteriores contribuciones, que continúa directamente hacia el S. por la quebrada de Talina en los establecimientos Inka de Chipihuaico y Chagua hasta llegar al tambo de Calahoyo, en la actual frontera boliviano-argentina para penetrar luego en el Noroeste argentino.

El restante se aparta hacia el oriente luego de transponer el río San Juan Mayo u Oro primero a la altura de Chuquiago-Charaja y luego más hacia el E. por Ñoquera, se divide en varios ramales en dirección a la Cordillera de los Chichas, los valles de Tarija y las yungas bolivianas, donde los Inka instalaron su frontera oriental protegida por guarniciones defensivas para controlar las periódicas invasiones chiriguanas. 
2- El estado Inka explotó los valles fértiles que bajan del altiplano de Potosí, Chuquisaca y Potosí en dirección a las yungas del oriente boliviano y el chaco saltojujeño de Argentina. Estos valles son los de Pilaya, Chaguaya, Padcaya, Camacho, Antigal, Choloca y Tarija, con producciones de maíz, coca, tomate, ají, calabazas y recolección de frutas dulces y algodón. Hizo lo propio también con las quebradas altas de Santa Victoria, Nazareno, Iruya, San Andrés y los valles de Lerma-Salta y Vallegrande de Jujuy. Para ello utilizó mitmaq y jatumrunas provenientes de los señoríos locales conquistados, a los que ocupó en la construcción de espacios agrícolas (terrazas y canchones con sistemas de irrigación) y construcciones de almacenaje (collcas).

3- Las etnias de la Quebrada de Humahuaca, uno de los más relevantes valles tipo keshua del extremo boreal argentino, formaron parte de este sistema colonial impuesto por el Tawantinsuyu. Así lo atestiguan importantes establecimientos que responden a los señoríos locales preexistentes que fueron incorporados al Estado a partir de la segunda mitad del siglo XV. Entre ellos Tilcara, La Huerta, Yacoraite, Coctaca, Cerro Morado y los Amarillos, a la vez que una sucesión de tambos y segmentos viales que la surcan longitudinalmente desde su cabecera N. ya reconocidos en anteriores aportes (Raffino 1981 y 1993; Nielsen 1997).

4- En estas regiones y como producto de tal dominio se registran más de medio centenar de instalaciones pertenecientes al Tawantinsuyu situadas desde el borde meridional del Lago Poopó o Aullagas de Bolivia hasta los valles del extremo boreal de Argentina (Raffino 1993, 232).

5-La energía agrícola produjo los recursos tendientes a suministrar el desarrollo minero de plata, oro, cobre, estaño y arsénico (los tres últimos usados en la metalurgia del bronce), que los Inka explotaban en la cadena montañosa de Porco, Tupiza y Chayanta en la Cordillera Central o Real de Bolivia. Similar situación ocurre en Chuquiago (Polvo fino de oro en kechua) del Valle de Suipacha y en otros lugares del mencionado río San Juan Oro, donde los Inka, simultáneamente, utilizaban mitmaq además de las etnias locales como mano de obra.

6- Para llevar a cabo dichas actividades fue necesario construir varios ramales del capacñam, tambos o postas de aprovisionamiento y pucarás defensivos. Entre los establecimientos Inka son reconocibles los de El Saire, Chasquiwasi Cementerio, Tullkumarka, Calderillas, Tajzara (tambo y corrales agrupados), Noquera (puente y tambo), las guarniciones de Charaja y Condorhuasi, Sama (puente y capacñam), Tolomosa (tambo y cementerio), Tullkumarca y Chocloca (tambo, campos agrícolas y collcas) y Livi Livi (dos tambos).

7- Esta infraestructura Inka fue construida cruzando transversalmente la geografía, de O. a E., uniendo los valles de Tarija con las áreas de desarrollo económico y con el capacñam o camino principal que conectaba Cuzco con Tupiza y el Noroeste de Argentina y Chile (Raffino 1982, 1986, 1993).

8- La red vial o capacñam se construyó en parte sobre caminos preexistentes a la conquista regional del Tawantinsuyu, durante el Período Intermedio Tardío o de Desarrollos Regionales, realizados seguramente por las jefaturas preinkas Chichas, Tomatas y 
Churumatas. Algunos de estos caminos fueron remodelados por los Inka, como por ejemplo el capacñam que conecta los sitios de Copacabana-Torohuaico-CampanarioCamacho y la conexión entre el establecimiento Inka de Tullkumarka con Misca y Pinos.

En general, este sistema vial atravesó la cadena montañosa de Chichas. Para ello, los caminos debieron ser construidos con una técnica de excelencia que les permitió atravesar las asperezas de la montaña. En esta elaboración son visibles los rasgos arquitectónicos clásicos del imperio Inka con otros que se muestran como típicos de la arquitectura regional producida por canteros y albañiles Chicha según lo señala el Memorial de Charcas (Espinoza Soriano 1969) y el registro arqueológico de estos sitios.

Otros tramos del camino son sendas sin base arquitectónica y responden, claramente, a rutas de tránsito históricas, algunas de las cuales han trascendido hasta la actualidad y corresponden al tráfico de salineros que descienden del altiplano hacia los valles llevando sus cargas. (Nielsen 1998).

9- Con excepción de algunos tiestos y vasijas aisladas durante nuestros trabajos de campo, no hemos hallado ninguna evidencia arquitectónica que indique presencia efectiva de asientos del momento Tiwanaku Clásico del Lago Titicaca.

10- El estado Inka construyó, en su frontera oriental, en los confines del altiplano y los umbrales de las yungas que se interponen entre la región montañosa y la foresta chaqueña varias guarniciones o pukarás con arquitectura militar defensiva. Ellas son las de Charaja y Condorhuasi en el altiplano (Raffino 1993, 169 y ss.), (Lee 1992, 31), Culpina (Métraux 1933, 280), Batanes, Pucarilla, Pulquina e Incahuasi (Nordenskiöld 1924, 41 y ss.), Inkapirca y Manchachi (Lee, op.cit. ), Oroncotá y Cuzcotuyo (Lee, op.cit. Alconini 2002, 237). Estas fundaciones pucarás con arquitectura militar fueron creadas para garantizar la dominación de su espacio de las posibles invasiones de tribus chiriguanas y facilitar las comunicaciones y el flujo de servicios y provisiones por el capacñam entre el Noroeste argentino, Tarija y las minas de Potosí y Porco que explotaban.

11- Otras guarniciones son simples reductos carentes de arquitectura militar y fueron levantadas por pequeñas parcialidades locales en lo alto de los cerros probablemente en tiempos tanto anteriores como posteriores al horizonte Inka. Esta asignación correspondería a los reductos de Tomatas Grandes (mencionados en las crónicas y atribuidos a la parcialidad homónima), así como a las de San Lorenzo y Rincón Sola.

12- Además, el estado Inka fundó centros de alta complejidad donde confluían a tributar las etnias regionales y se cumplían funciones administrativas (redistributivas), entre ellos Samaipata (Meyer 1997) en el valle de Piray, borde entre los Andes y las Yungas; el mencionado Oroncotá en Chuquisaca (H. Walter 1959, S. Alconini 1993 y 2002), Chuquiago y Oma Porco en el altiplano potosino (Raffino 1993).

13- En cuanto a la existencia de obras de alto valor tecnológico, como el puente Inka asociado a un tambo en Ñoquera, su construcción revistió un notorio carácter estratégico. Ellos se emplazan al oriente del río San Juan Oro, justamente en un nudo caminero. Un «tinkuy Inka», encadenado a una serie de tambos situados al naciente y poniente 
de la vieja ruta Inka entre Tupiza-Tarija, utilizada seguramente luego, en 1539, por los invasores españoles Pedro de Candia y Diego de Rojas (Barragán Vargas 2001, 20).

14- El puente de Sama es otra obra compleja, construida inicialmente por los Inka y posteriormente remodelada en tiempos históricos. Posee dos estilos arquitectónicos diacrónicos, esto lo convierte en un conjunto «multicomponente», habida cuenta que aglutina rasgos Inkaicos y Chichas. En cuanto a su remodelación en tiempos coloniales, se hizo probablemente durante dos fases, también diacrónicas, que tienen que ver con el tráfico de caballos y mulares primero, y de carretones posteriormente, para conducir suministros desde Tarija hacia el altiplano de Porco y Tupiza, donde los Inka primero, y los españoles más tarde, explotaban las minas de oro, plata y cobre.

15- Tambos (tampus), caminos principales y secundarios (capacñam), guarniciones militares (pucarás), terrazas de agricultura, acueductos, puentes, collcas y apachetas, constituyen la infraestructura construida por mandato del Tawantinsuyu, que fue mantenida con el trabajo de grupos locales, antiguos dueños del territorio, quienes fueron participantes activos del Imperio Inka.

16- Estos caminos sobrevivieron al colapso del Tawantinsuyu y fueron transitados por los primeros conquistadores españoles que penetraron en los valles de Tarija, procedentes del Cuzco, hacia 1539, razón por la cual los primeros cronistas mencionan su existencia.

17- Al examinar la geografía donde se localizan estos registros arqueológicos, los cuales abarcan las cuencas del Pilcomayo y el Bermejo hasta las latitudes de Samaipata y Tariquia (esto significa sobre el meridiano de $64^{\circ} \mathrm{O}$ ), se comprueba que la expansión Inka alcanzó a invadir las comarcas boscosas del "espacio chiriguano". Hace algunos años hemos señalado evidencias arquitectónicas Inka, segmentos discontinuos de capacñam y pequeños tambos en la bajada de las yungas salteñas en el dique Las Pavas, en el Cerro Bravo de Santa Victoria Oeste y en el Parque El Baritú (Raffino 1993, 216).

\section{Una cuestión fronteriza}

No sabemos con certeza hasta que punto esta expansión fue seguida luego por un dominio territorial efectivo por el Tawantinsuyu. Aunque intuitivamente no lo creemos posible, tanto por tratarse de una difícil frontera por los factores ambientales, poco propicios para la adaptabilidad física de la gente de los Andes y el Altiplano (extensible a la falta de adaptación de la llama), como por la tantas veces señalada belicosidad de los chiriguanos.

Pero, aún así, el registro arqueológico es lo suficientemente claro como para conducirnos a compartir y ampliar las hipótesis ya sostenidas en cuanto a que los Inka y sus aliados Chichas, inclusive con la participación de otras jefaturas de la llamada confederación Charca, como los Churumatas, Tomatas, Erquis, Coimatas y Cuis, habían logrado avanzar sobre su frontera oriental hasta regiones de yungas entre los ríos Pilcomayo y Bermejo en el extremo austral de la actual Bolivia (Renard-Casevitz, Saignés y Taylor 1988).

Esta expansión se continuó por los territorios situados en el extremo boreal del actual territorio argentino al naciente de Humahuaca, alcanzando las latitudes de $64^{\circ}$ en los 
piedemontes orientales de las quebradas de Santa Victoria, Nazareno-Iruya, Vallegrande, Calilegua, Río Grande de Jujuy y San Francisco. La existencia de un tambo Inka a la altura del Dique Las Pavas significa una posición de 50 kilómetros aguas arriba de la confluencia entre los ríos Bermejo y Tarija, ya en el bosque espinoso del chaco salteño. En este caso, valiéndose probablemente de una intervención de mitmas obtenidos de las jefaturas Omaguacas, o de parcialidades como los Ocloyas y Churumatas.

Este avance provocado por el Estado Inka y sus aliados del altiplano y los valles mesotérmicos hacia las yungas meridionales fue una verdadera cabeza de puente durante fines del siglo XV hasta la caída del Tawantinsuyu. Una frontera determinada por la geografía y la incompatibilidad étnica entre la cultura andina y los "antis" amazónicos, los "moxos" del Beni y sus parientes chiriguanos del gran Chaco.

Una frontera móvil, seguramente una faja gris que se expandía o retrocedía como un gigantesco diafragma por imperio de los logros de uno u otro bando. El mundo andino versus el "del bajo". Los Inkas y sus aliados Chichas, Churumatas, Carangas, etc., pudieron defenderla no sin dificultades entre fines del siglo XV y primer tercio del XVI.

Esa frontera sufriría luego un importante retroceso durante el primer siglo de los tiempos hispánicos. Son conocidas las enormes dificultades que tuvieron los españoles para "colonizar" el bosque chaqueño, tanto del lado boliviano (Renard-Casevitz, Saignés y Taylor 1988, 261) como del argentino (Maeder 1996, 28).

Las tempranas fundaciones de Santa Cruz de La Sierra (1557) y Concepción del Bermejo (1585) por las corrientes paraguayas comandadas por Nuflo de Chávez y luego por Alonso de Vera; así como la de Tarija (1574) por la andina de Luis de Fuentes y Vargas, respondieron a claras intenciones de la Corona por tomar posesión efectiva de la región.

Sin embargo, durante mucho tiempo esa frontera dinámica no pudo ser sostenida, sufriendo una evidente retracción ante la imposibilidad de contener las innumerables incursiones chiriguanas acaecidas a partir de la segunda mitad del siglo XVI, una vez fenecido el dominio Inka.

Estas investigaciones sobre secciones del capacñam, sus tampus de apoyo, pucarás y centros agrícolas Inka en latitudes comprendidas entre los extremos austral de Bolivia y septentrional de Argentina fueron posibles por obra de 7 misiones al terreno financiadas por National Geographic Society (R. Raffino, Grant 2834/1984, Grant 4430/1991 y Grant 7126/2001).

El director de este proyecto agradece la valiosa colaboración del Arquitecto Ricardo J. Alvis (1948-1995) en las tres primeras misiones al terreno, del Dr. Axel Nielsen durante la tercer misión (1987) y del Licenciado Cristian Vitry en las tres últimas (2002-2003).

Nuestra gratitud a los residentes de Tupiza y Tarija por su apoyo, al maestro Juan Mogros, el arqueólogo Dante Angelo de Tupiza, a Phillipe Delcourt de Padcaya y a la familia Methffessel. En el ordenamiento y sistematización de los informes de terreno en gabinete ha participado el Lic. Reinaldo Moralejo (CONICET). 


\section{Cuadro I}

Posiciones de las instalaciones Inka (X) o con componentes inkas (\#), en la ruta Potosí-Tarija.

\begin{tabular}{|c|c|c|c|c|c|}
\hline Nombre & Latitud S. & Longitud W. & Altura & Comp. Inka & Obs. \\
\hline Chuquiago & $21^{\circ} 34^{\prime} 5^{\prime \prime}$ & $65^{\circ} 38^{\prime} 30^{\prime \prime}$ & 2830 & $\mathrm{X}$ & Gps \\
\hline Villa Victoria & $21^{\circ} 35^{\prime} 30^{\prime \prime}$ & $65^{\circ} 36^{\prime} 50^{\prime \prime}$ & 2840 & $\mathrm{X}$ & Gps \\
\hline Charaja & $21^{\circ} 35^{\prime} 40^{\prime \prime}$ & $65^{\circ} 34^{\prime} 15^{\prime \prime}$ & 3010 & $\mathrm{X}$ & Gps \\
\hline Livi-Livi o Villa Pacheco & $21^{\circ} 41^{\prime} 55^{\prime \prime}$ & $65^{\circ} 18^{\prime} 20^{\prime \prime}$ & 2540 & $X$ & Gps \\
\hline Quiscacancha & $21^{\circ} 37^{\prime} 45^{\prime \prime}$ & $65^{\circ} 10^{\prime} 10^{\prime \prime}$ & 3320 & & Gps \\
\hline Ñoquera puente & $21^{\circ} 37^{\prime} 30^{\prime \prime}$ & $65^{\circ} 8^{\prime} 15^{\prime \prime}$ & 3410 & $\mathrm{X}$ & Gps \\
\hline Noquera tambo & $21^{\circ} 37^{\prime} 35^{\prime \prime}$ & $65^{\circ} 7^{\prime} 54^{\prime \prime}$ & 3440 & $\mathrm{X}$ & Gps \\
\hline Sn. Luis de Palqui & $21^{\circ} 33^{\prime}$ & $65^{\circ} 8^{\prime}$ & 3300 & & Cart. \\
\hline Apacheta pampa rayo & $21^{\circ} 30^{\prime} 50^{\prime \prime}$ & $65^{\circ} 1^{\prime} 20^{\prime \prime}$ & 4090 & $X$ & Gps \\
\hline Condorhuasi & $21^{\circ} 28^{\prime}$ & $65^{\circ} 2^{\prime}$ & 3900 & $\mathrm{X}$ & Cart. \\
\hline Puente de Sama & $21^{\circ} 29^{\prime} 10^{\prime \prime}$ & $64^{\circ} 53^{\prime} 40^{\prime \prime}$ & 3700 & \# & Gps \\
\hline Fuerte de Marquiri & $21^{\circ} 24^{\prime} 20^{\prime \prime}$ & $64^{\circ} 51^{\prime} 15^{\prime \prime}$ & 2500 & & Gps \\
\hline Tajsara (tambo) & $21^{\circ} 44^{\prime} 35^{\prime \prime}$ & $65^{\circ} 1^{\prime} 50^{\prime \prime}$ & 3700 & $\mathrm{X}$ & Gps \\
\hline Tajsara (corrales) & $21^{\circ} 44^{\prime} 50^{\prime \prime}$ & $65^{\circ} 4^{\prime} 10^{\prime \prime}$ & 3650 & $\mathrm{X}$ & Gps \\
\hline Calderillas & $21^{\circ} 45^{\prime} 0^{\prime \prime}$ & $64^{\circ} 57^{\prime} 40^{\prime \prime}$ & 3040 & $\mathrm{x}$ & Gps \\
\hline El Mesón & $21^{\circ} 45^{\prime} 15^{\prime \prime}$ & $64^{\circ} 54^{\prime} 40^{\prime \prime}$ & 2400 & $\mathrm{X}$ & Gps \\
\hline Pinos & $21^{\circ} 44^{\prime} 50^{\prime \prime}$ & $64^{\circ} 53^{\prime} 25^{\prime \prime}$ & 2150 & & Gps \\
\hline Turku Marka & $21^{\circ} 49^{\prime} 20^{\prime \prime}$ & $64^{\circ} 55^{\prime} 30^{\prime \prime}$ & 2300 & \# & Gps \\
\hline Pozuelos & $21^{\circ} 46^{\prime} 50^{\prime \prime}$ & $65^{\circ} 9^{\prime} 55^{\prime \prime}$ & 4050 & & Cart. \\
\hline Torohuaico & $21^{\circ} 52^{\prime} 30^{\prime}$ & $65^{\circ} 0^{\prime} 25^{\prime \prime}$ & 4200 & $\mathrm{X}$ & Gps \\
\hline Chasquihuasi (Camacho) & $21^{\circ} 53^{\prime} 50^{\prime}$ & $64^{\circ} 55^{\prime} 20^{\prime}$ & 2250 & $\mathrm{X}$ & Gps \\
\hline Apacheta (Camacho) & $21^{\circ} 52^{\prime} 55^{\prime \prime}$ & $64^{\circ} 58^{\prime} 15^{\prime \prime}$ & 3250 & $\mathrm{X}$ & Gps \\
\hline Queñahuaico & $21^{\circ} 56^{\prime} 30^{\prime \prime}$ & $64^{\circ} 57^{\prime} 40^{\prime \prime}$ & 2580 & & Gps \\
\hline Chocloca & $21^{\circ} 45^{\prime} 55^{\prime}$ & $64^{\circ} 44^{\prime} 30^{\prime \prime}$ & 1800 & $\mathrm{X}$ & Gps \\
\hline Saire & $21^{\circ} 55^{\prime} 50^{\prime}$ & $64^{\circ} 42^{\prime} 30^{\prime \prime}$ & 1890 & $\mathrm{X}$ & Gps \\
\hline Samaipata & $18^{\circ} 10^{\prime}$ & $63^{\circ} 51^{\prime}$ & 1640 & $\mathrm{X}$ & Cart. \\
\hline Tariquia & $21^{\circ} 58^{\prime}$ & $64^{\circ} 24^{\prime}$ & 1260 & $\mathrm{X}$ & Cart. \\
\hline Tomatas Grande & $21^{\circ} 18^{\prime}$ & $64^{\circ} 48^{\prime}$ & 2500 & & Cart. \\
\hline San Lorenzo & $21^{\circ} 25^{\prime}$ & $64^{\circ} 45^{\prime}$ & 2100 & & Cart. \\
\hline Rincón Sola & $21^{\circ} 38^{\prime} 15^{\prime \prime}$ & $64^{\circ} 52^{\prime} 20^{\prime \prime}$ & 2240 & & Gps \\
\hline Mecoya & $22^{\circ} 6^{\prime} 9^{\prime \prime}$ & $64^{\circ} 53^{\prime} 50^{\prime \prime}$ & 2300 & & Cart. \\
\hline Titiconte & $22^{\circ} 47^{\prime} 4^{\prime \prime}$ & $65^{\circ} 12^{\prime} 5^{\prime \prime}$ & 3000 & $\mathrm{X}$ & Cart. \\
\hline Arcayo & $22^{\circ} 46^{\prime} 53^{\prime \prime}$ & $65^{\circ} 5^{\prime} 51^{\prime \prime}$ & 2200 & $\mathrm{X}$ & Cart. \\
\hline Zapallar & $22^{\circ} 42^{\prime} 7^{\prime \prime}$ & $65^{\circ} 7^{\prime} 8^{\prime \prime}$ & 2300 & $\mathrm{X}$ & Cart. \\
\hline Nazareno & $22^{\circ} 30^{\prime} 24^{\prime \prime}$ & $65^{\circ} 6^{\prime} 18^{\prime \prime}$ & 3200 & $\mathrm{X}$ & Cart. \\
\hline Las Pavas & $22^{\circ} 29^{\prime} 11^{\prime \prime}$ & $64^{\circ} 31^{\prime} 39^{\prime \prime}$ & 800 & & \\
\hline Rodeo Colorado & $22^{\circ} 37^{\prime} 53^{\prime \prime}$ & $65^{\circ} 11^{\prime} 27^{\prime \prime}$ & 3300 & $\mathrm{X}$ & Cart. \\
\hline San Pedro & $22^{\circ} 38^{\prime} 18^{\prime}$ & $65^{\circ} 7^{\prime} 24^{\prime \prime}$ & 2400 & $\mathrm{X}$ & Cart. \\
\hline Puerta de Zenta & $23^{\circ} 10^{\prime}$ & $65^{\circ} 5^{\prime}$ & 4000 & $\mathrm{X}$ & Cart. \\
\hline Cerro Amarillo & $23^{\circ} 33^{\prime}$ & $64^{\circ} 54^{\prime}$ & 3600 & $X$ & Cart. \\
\hline Pueblito Calilegua & $23^{\circ} 33^{\prime}$ & $64^{\circ} 54^{\prime}$ & 2600 & $\mathrm{X}$ & Cart. \\
\hline Co. Chasquillas & $23^{\circ} 24^{\prime}$ & $65^{\circ} 8^{\prime}$ & 4200 & $\mathrm{X}$ & Cart. \\
\hline
\end{tabular}

En la columna de observaciones se consignan los datos de las localizaciones según sean tomados con gps o por cartografía. 
Figura 1: Mapa de situación

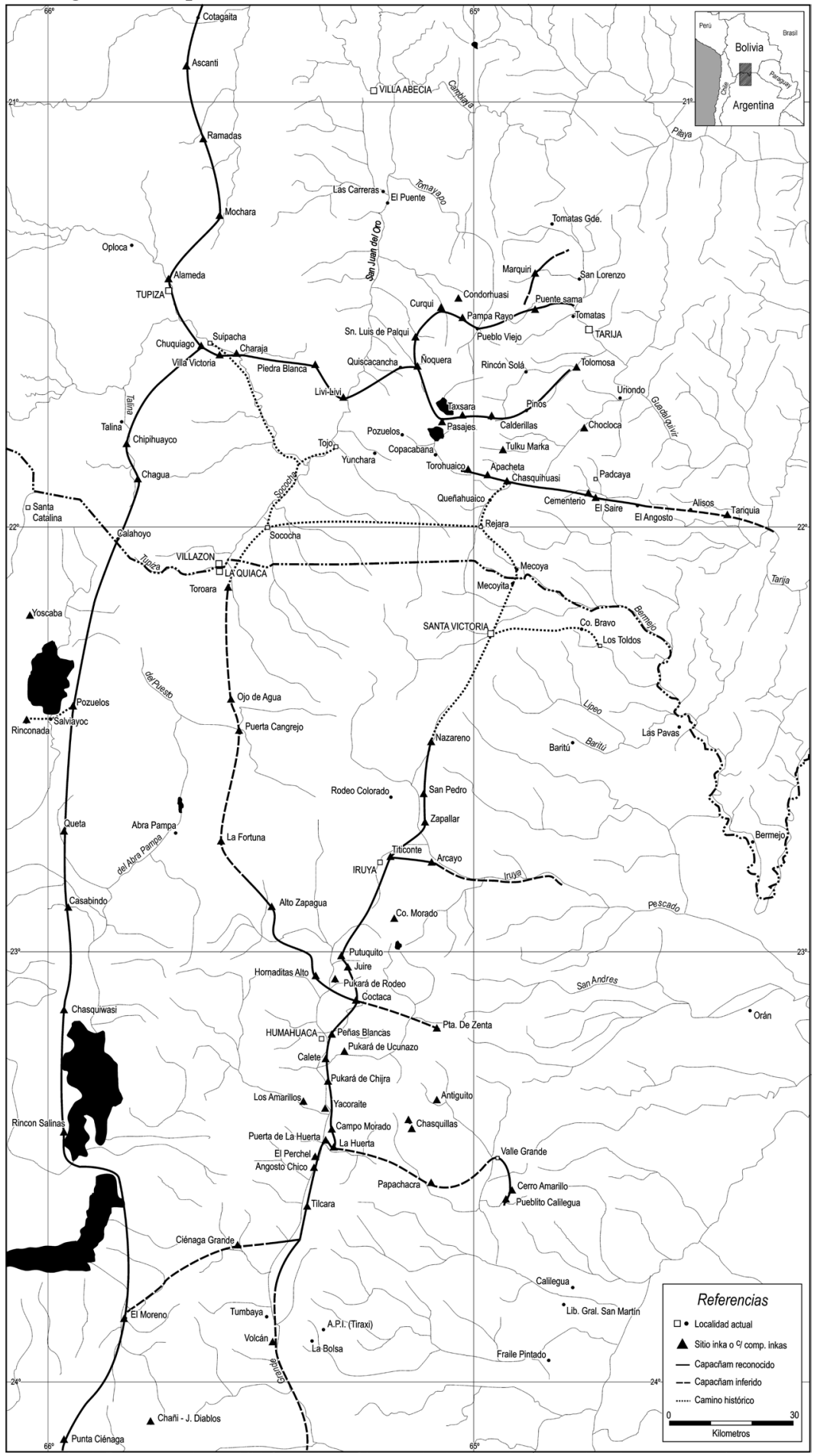


Folia Histórica del Nordeste, Nº 16 (Resistencia, 2006) IIGHI, CONICET - IH, UNNE)
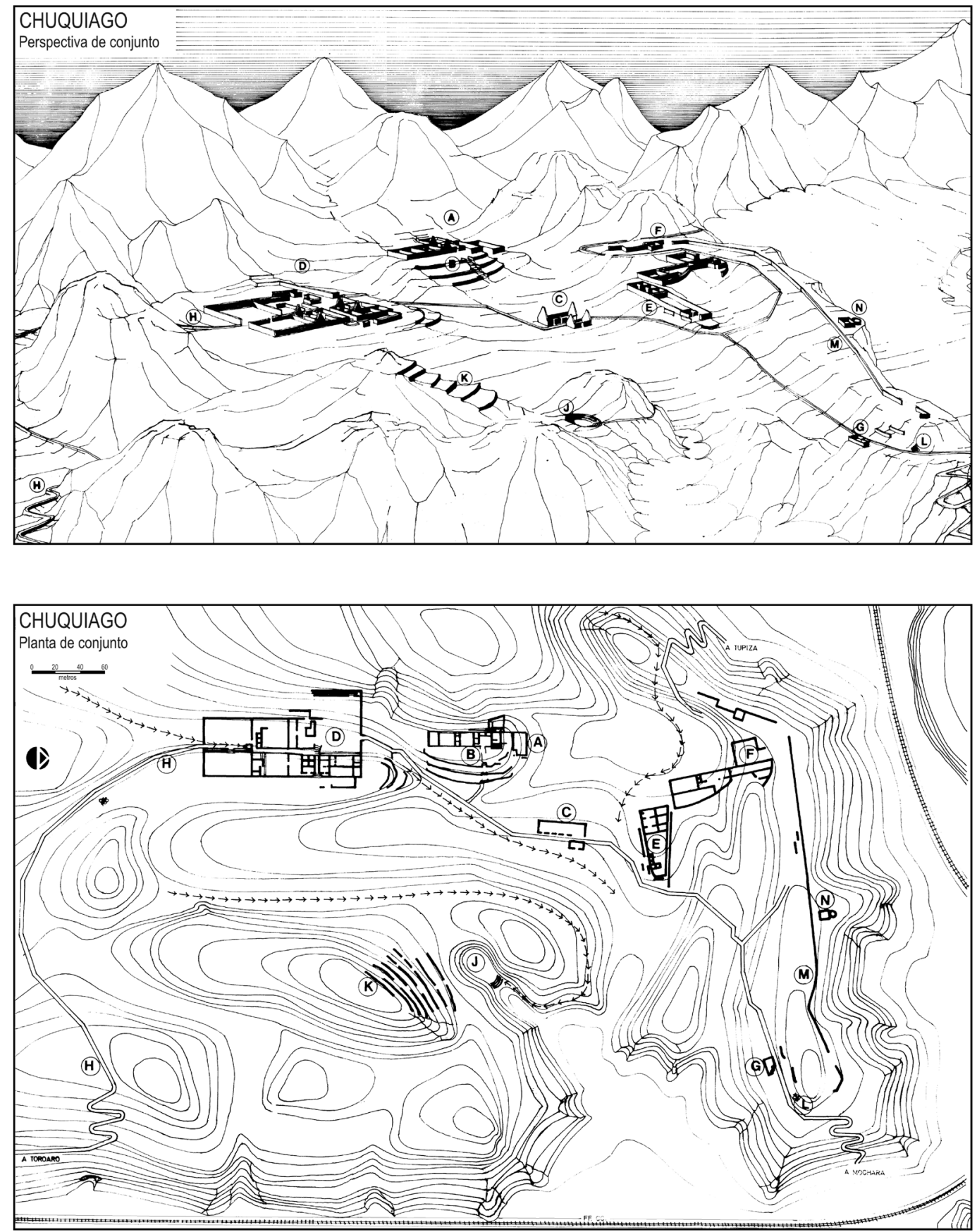

Figura 2: Planta y perspectiva de Chuquiago de Suipacha 
Folia Histórica del Nordeste, Nº 16 (Resistencia, 2006) IIGHI, CONICET - IH, UNNE)

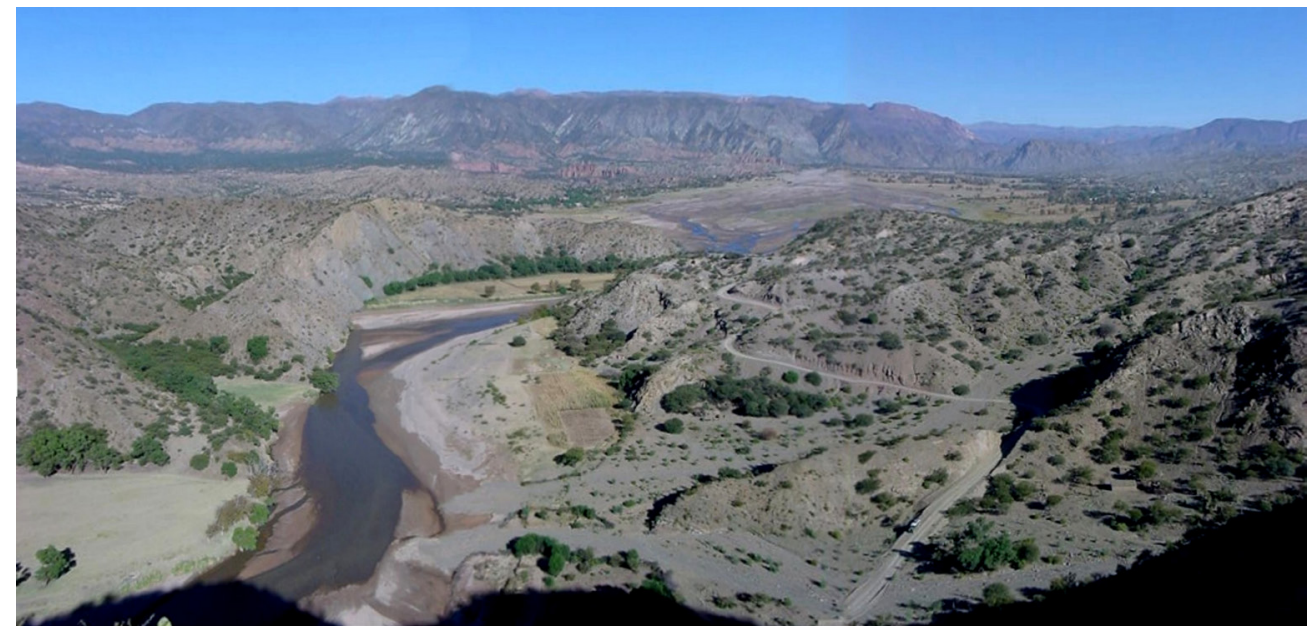

Figura 3: El Río San Juan Oro visto desde las alturas del pucará de Charaja

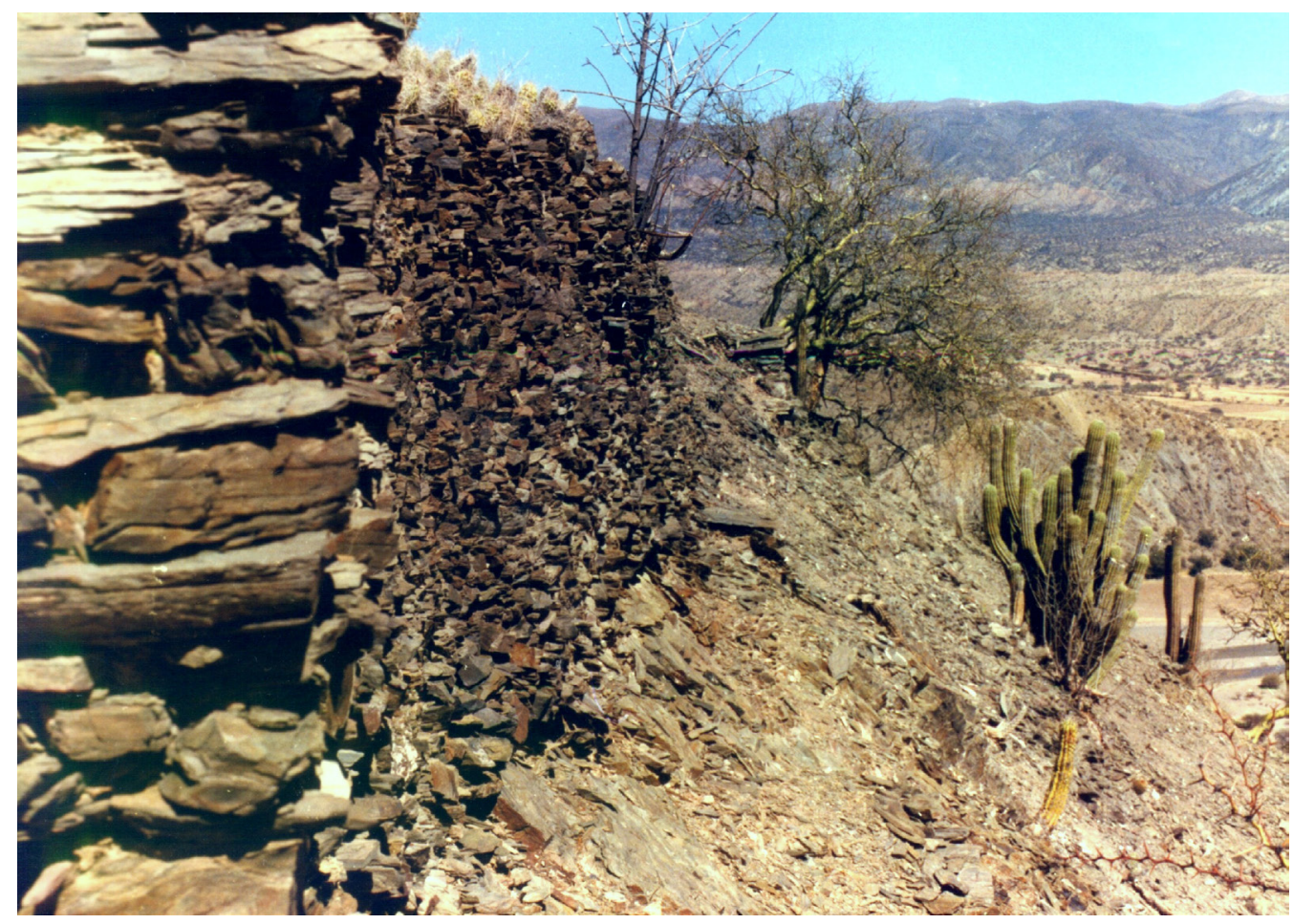

Figura 4: Muralla defensiva y croquis del pucará de Charaja 


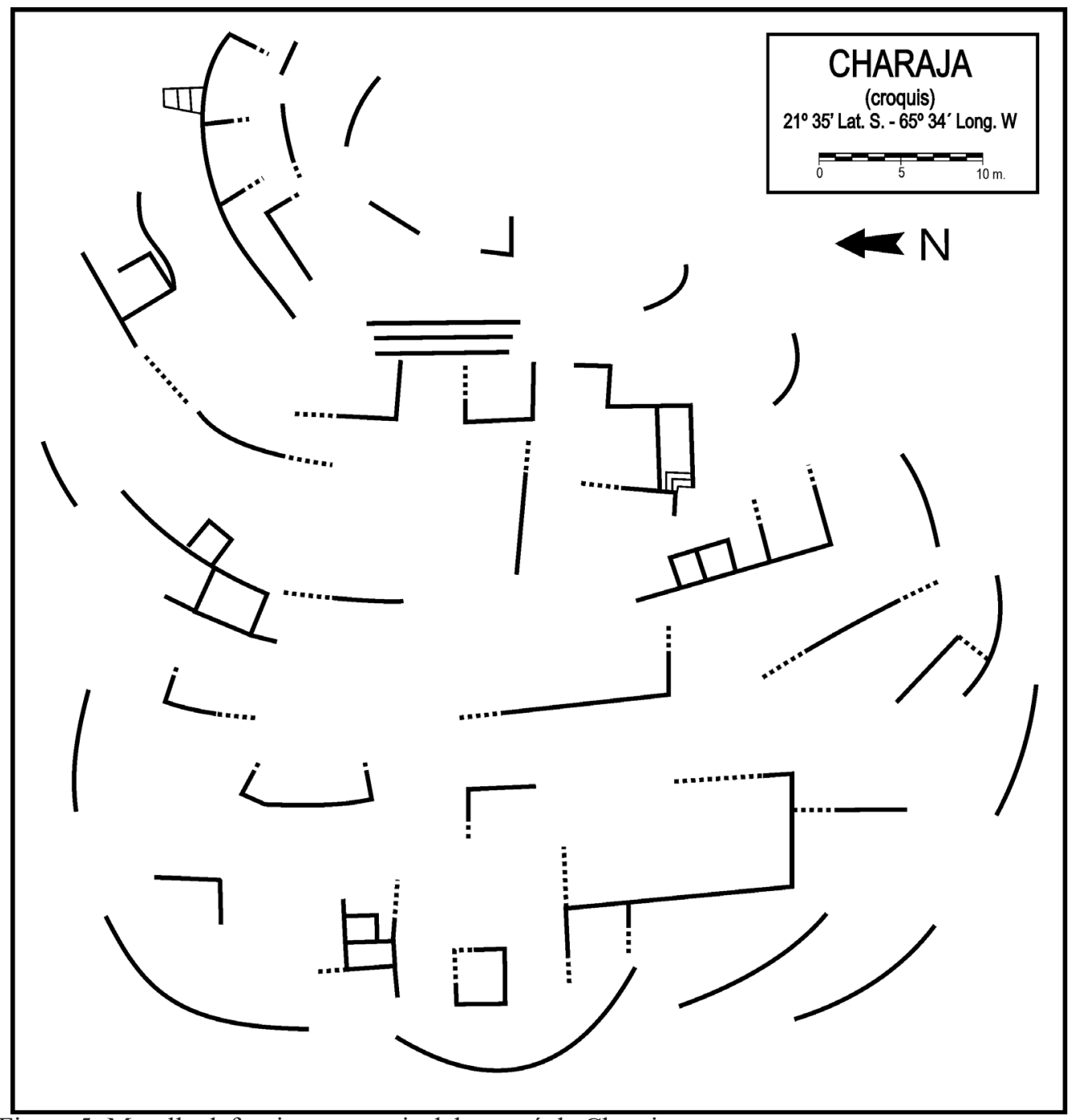

Figura 5: Muralla defensiva y croquis del pucará de Charaja 
Folia Histórica del Nordeste, $\mathbf{N}^{0} 16$ (Resistencia, 2006) IIGHI, CONICET - IH, UNNE)

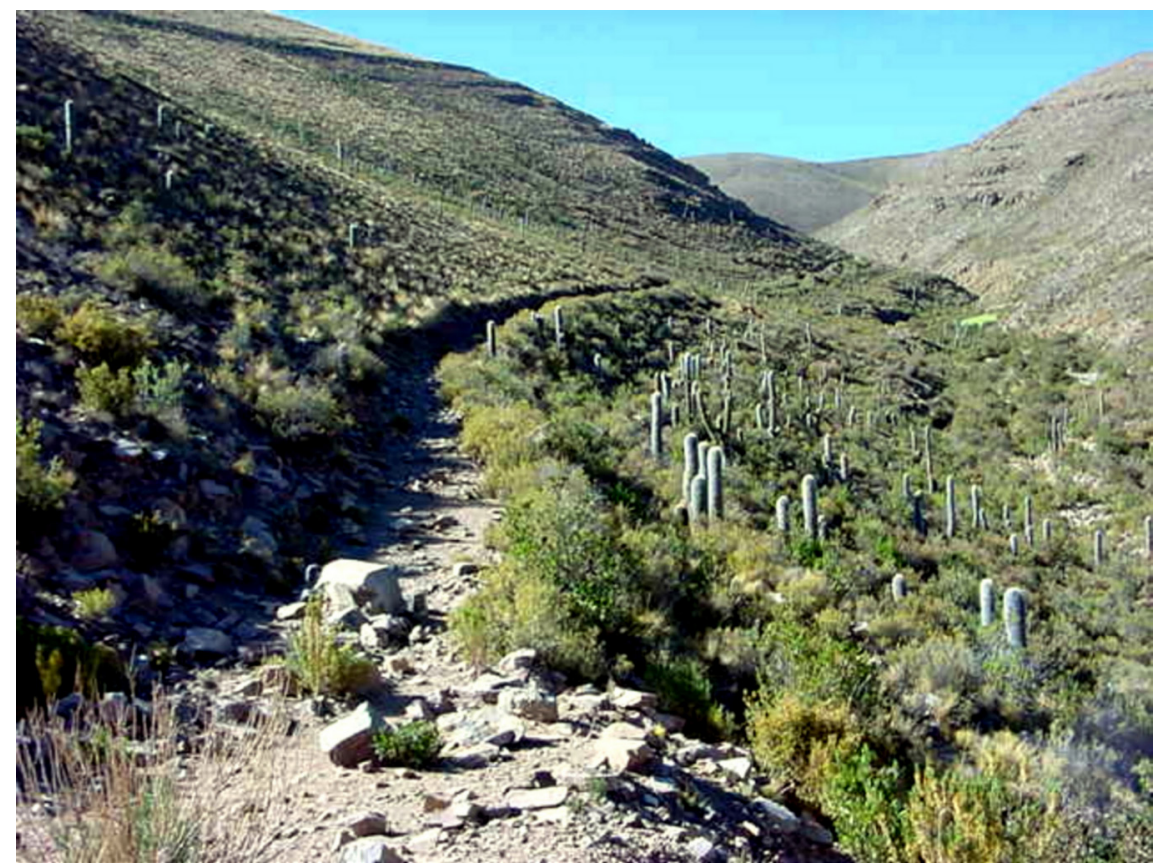

Figura 6 y 7: El Capacñam en Piedra Blanca y tambo y croquis de Liviv-Livi en Potosí

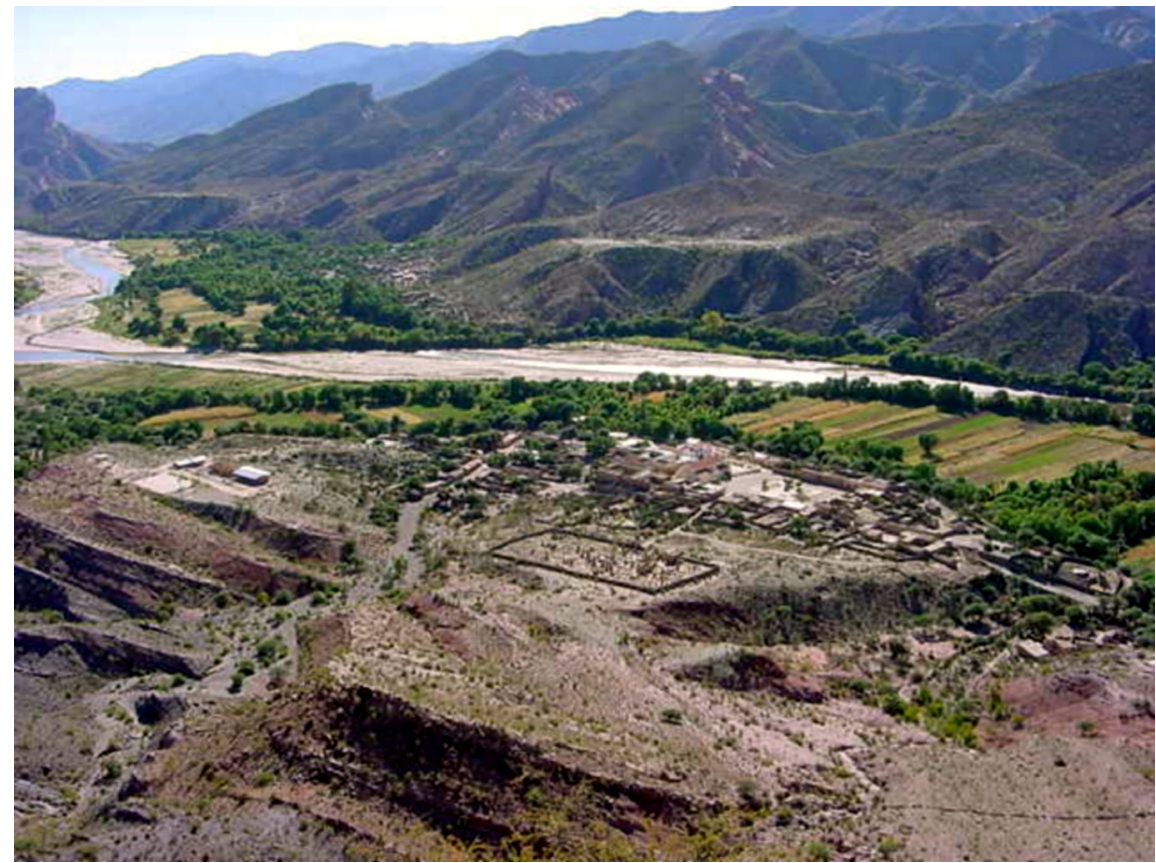


Folia Histórica del Nordeste, № 16 (Resistencia, 2006) IIGHI, CONICET - IH, UNNE)

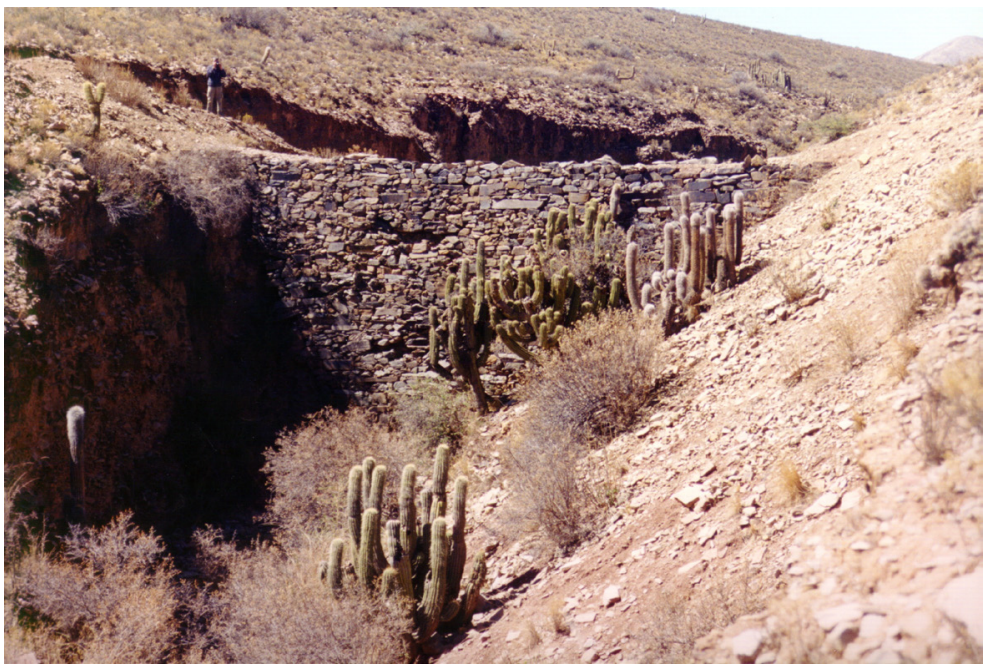

Figura 9 y 10: El rumichaca y tambo de Ñoquera

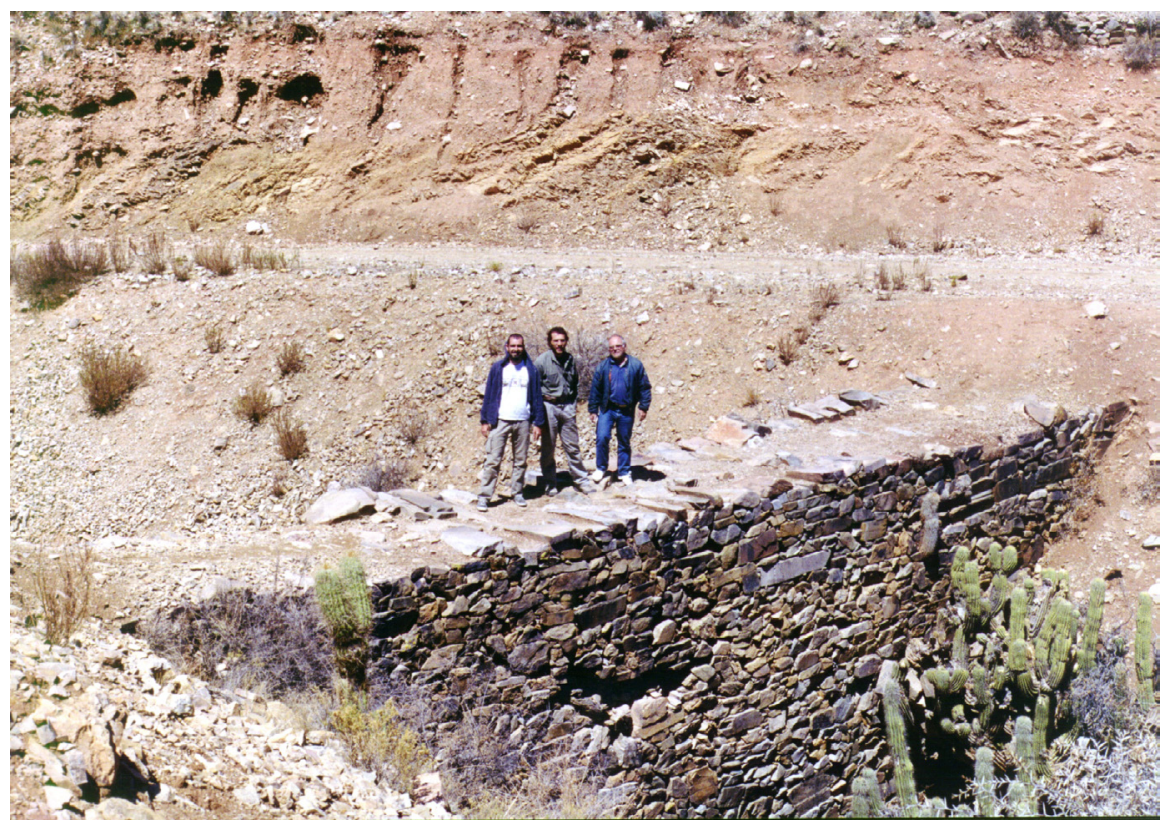


Folia Histórica del Nordeste, No 16 (Resistencia, 2006) IIGHI, CONICET - IH, UNNE)

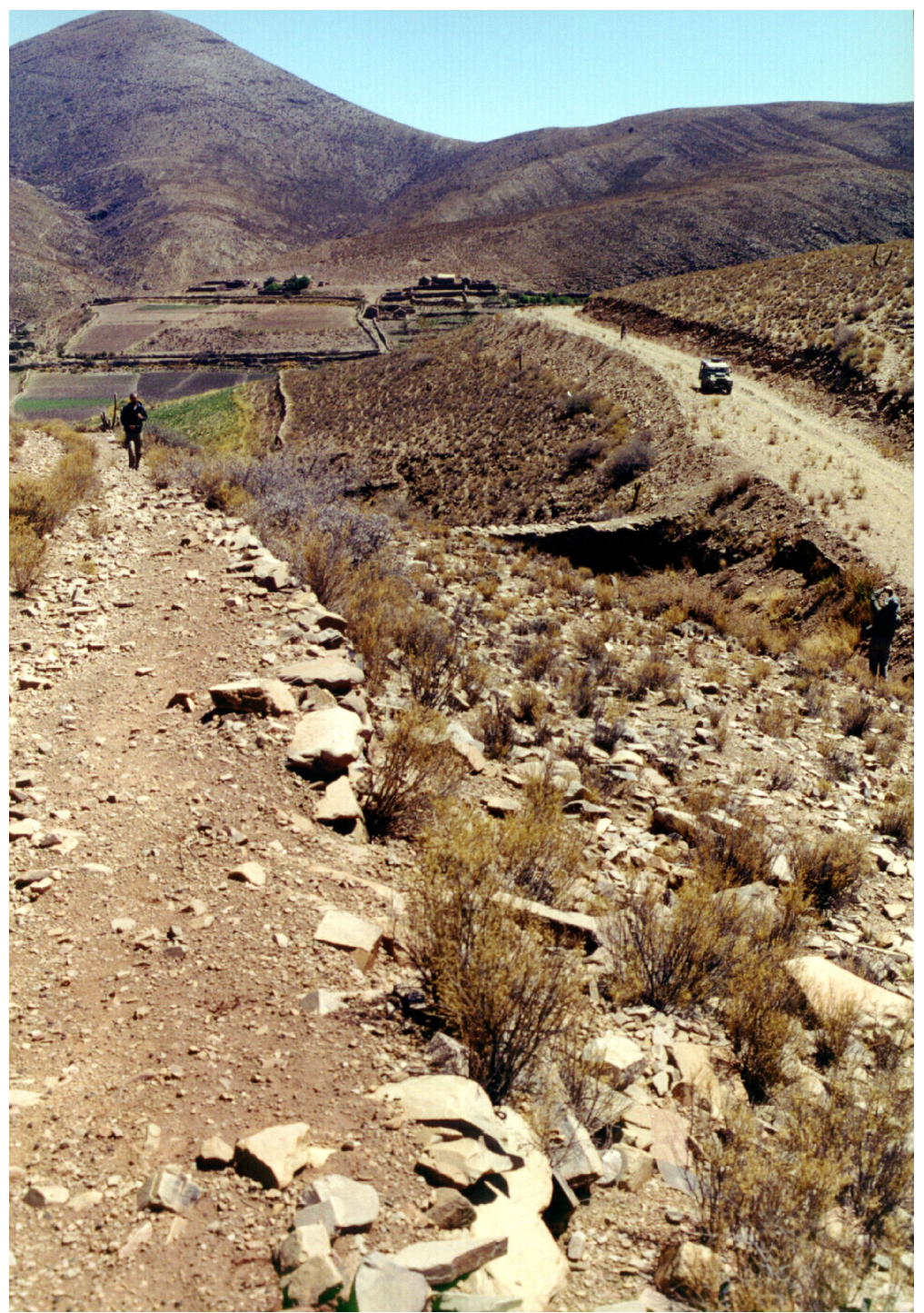

Figura 11: El rumichaca y tambo de Ñoquera 
Folia Histórica del Nordeste, $\mathbf{N}^{0} 16$ (Resistencia, 2006) IIGHI, CONICET - IH, UNNE)

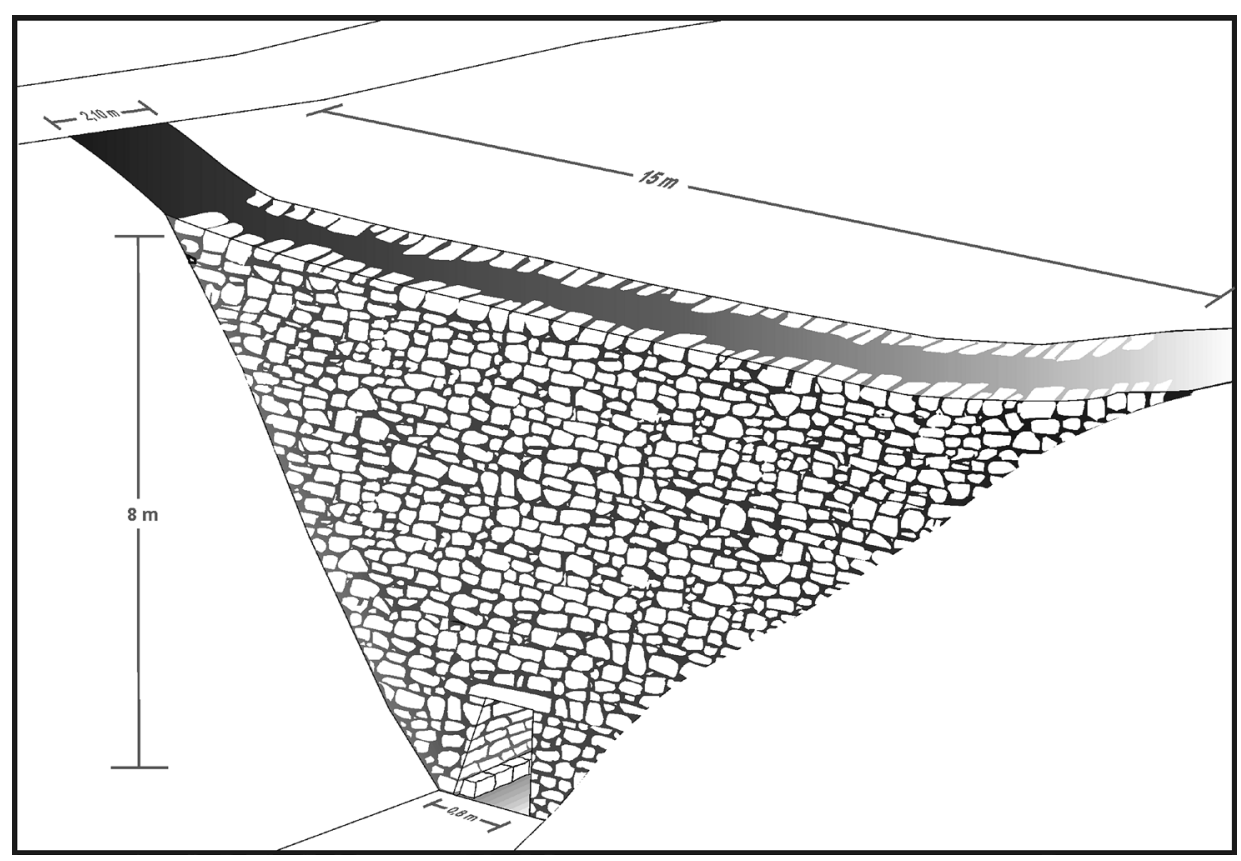

Figura 12 y 13: El rumichaca y tambo de Ñoquera

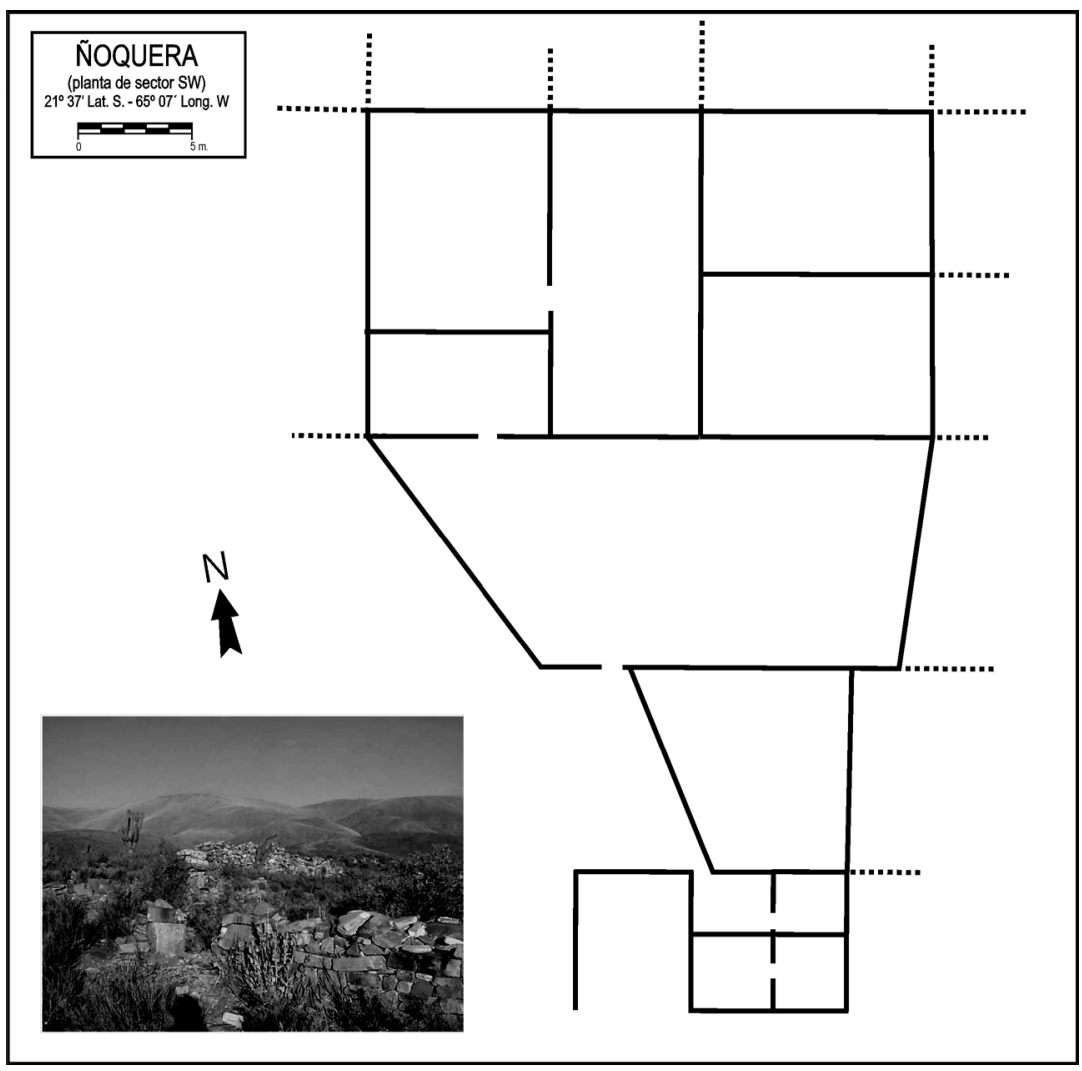




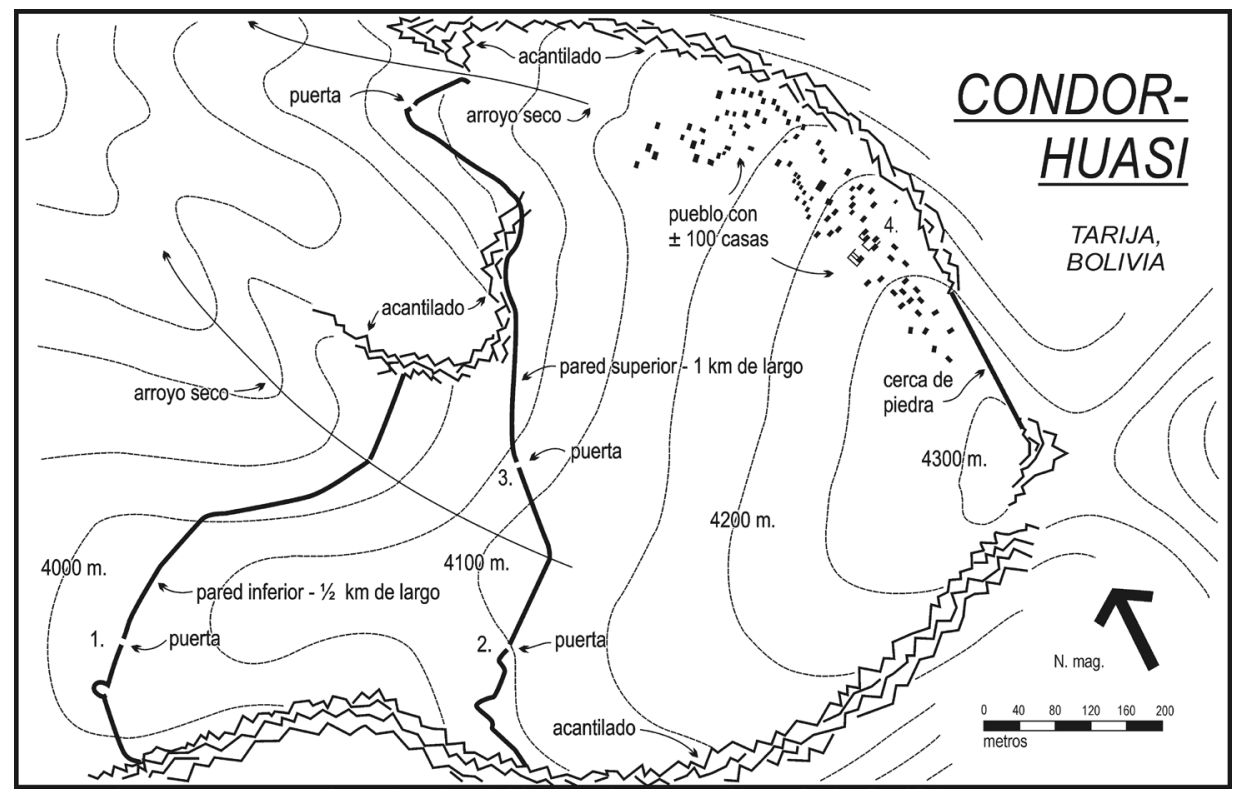

Figura 14 y 15: Planta e imágenes del Pucará de Condorhuasi

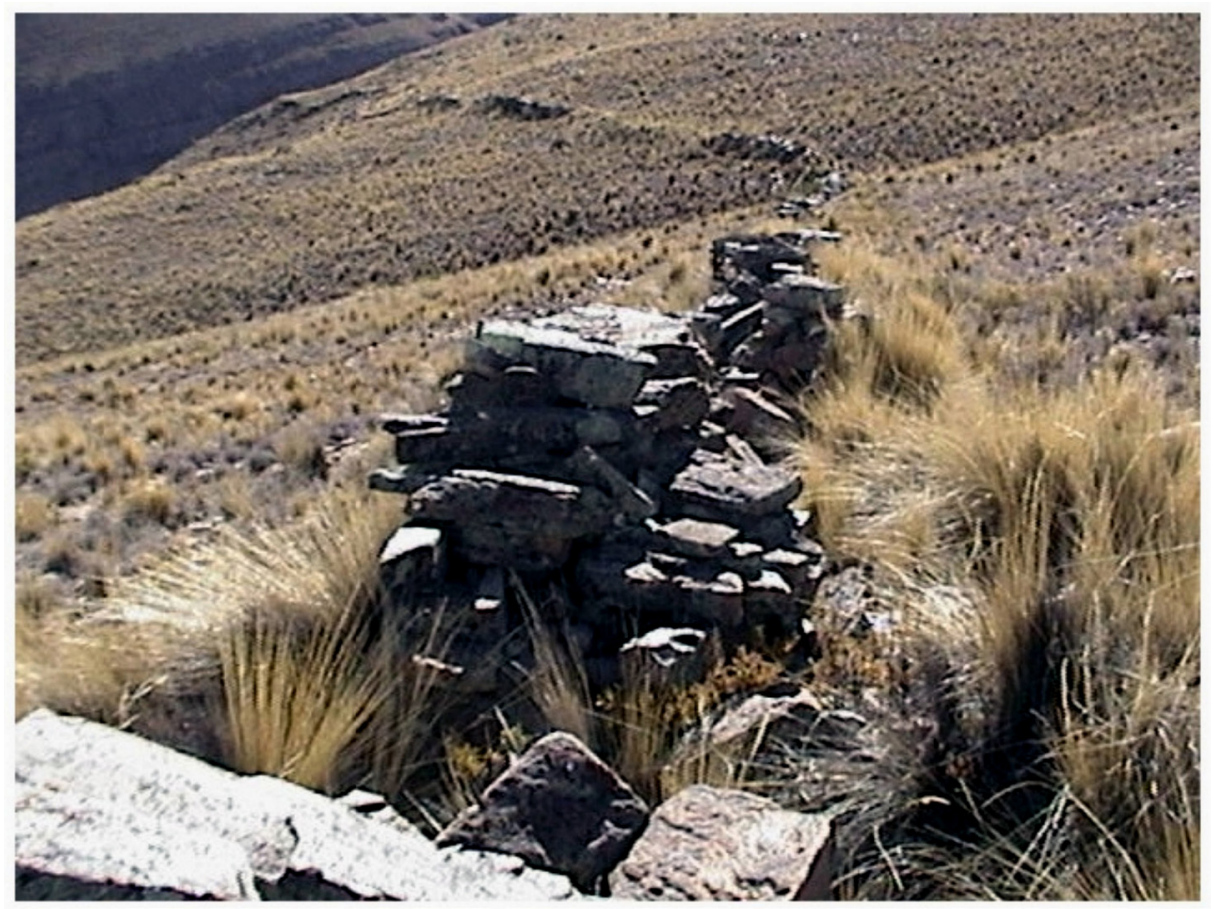


Folia Histórica del Nordeste, N$^{0} 16$ (Resistencia, 2006) IIGHI, CONICET - IH, UNNE)

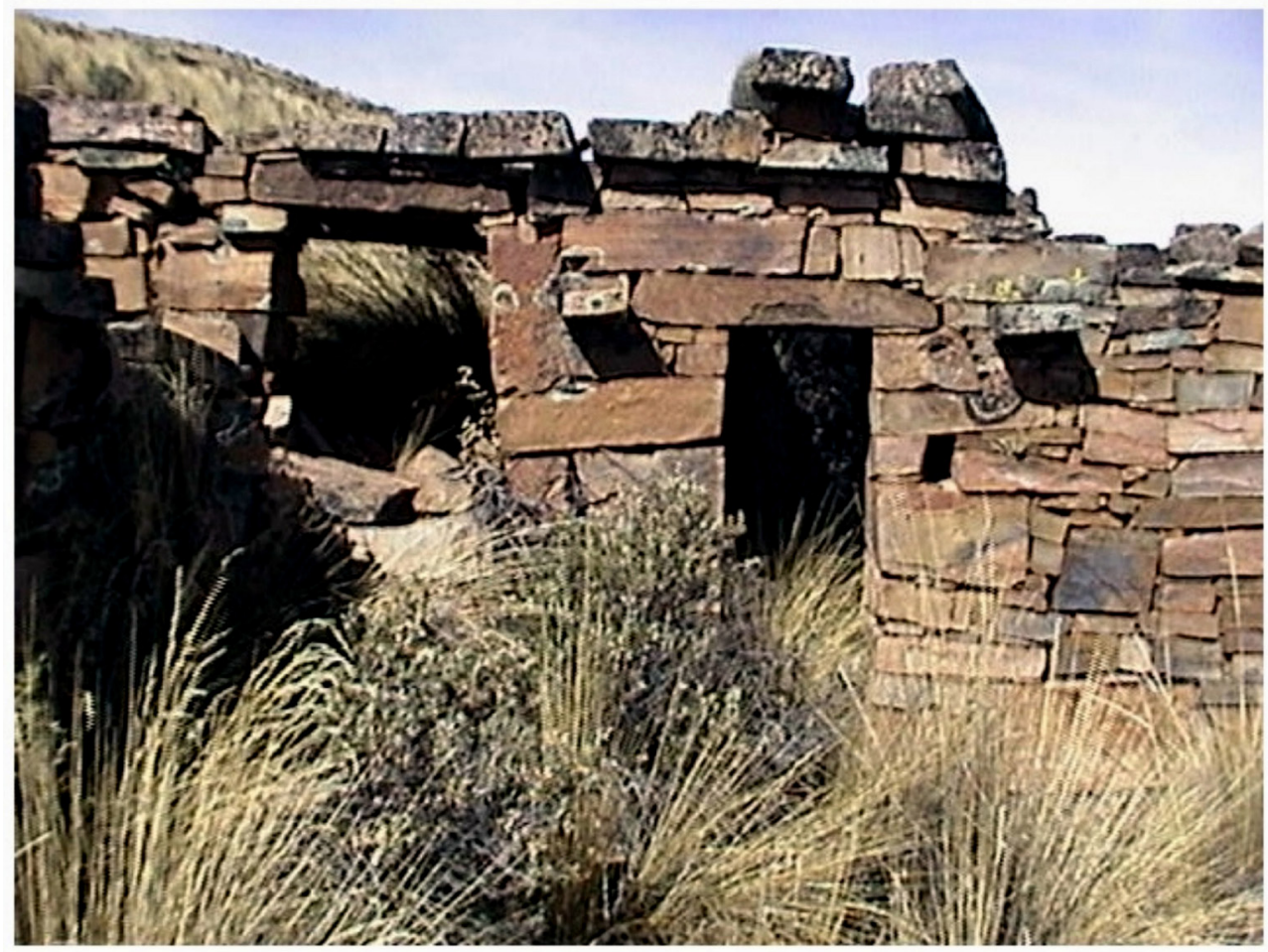

Figura 15: Imagen del Pucará de Condorhuasi

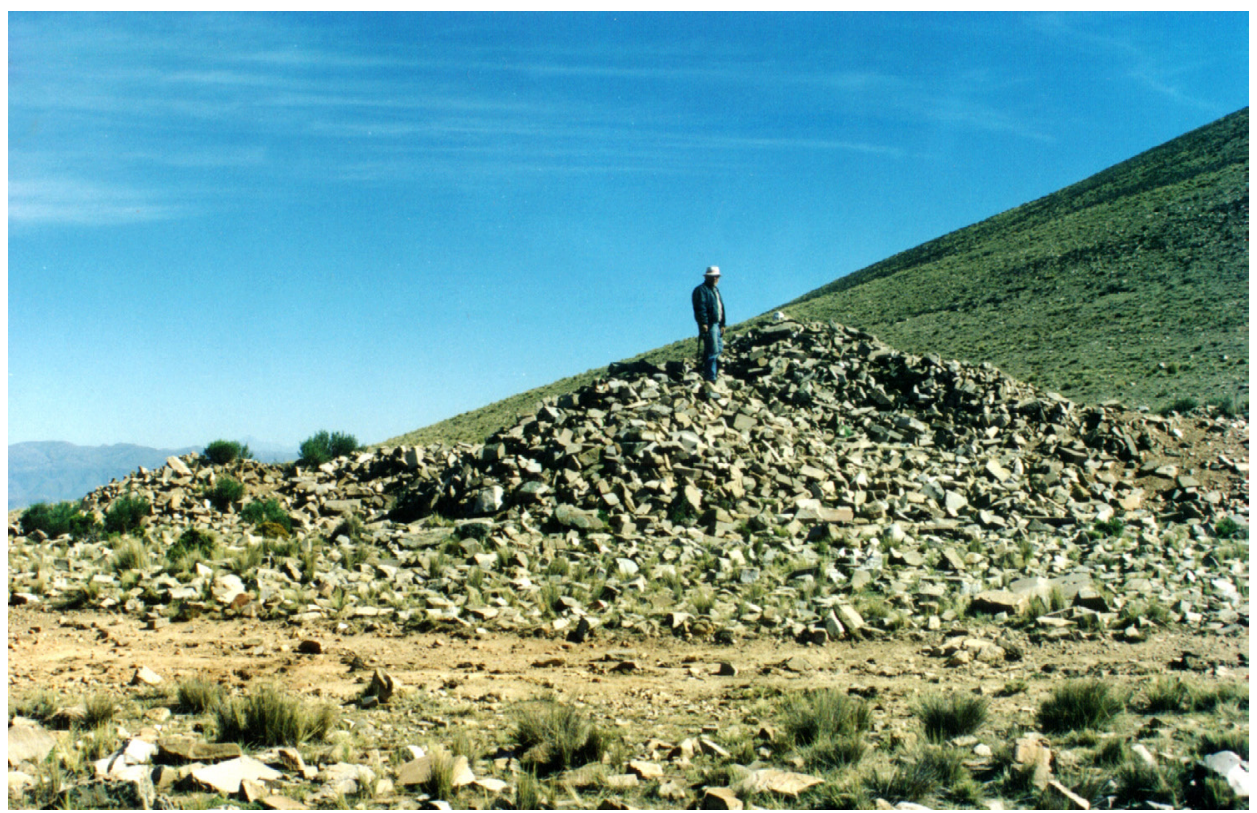




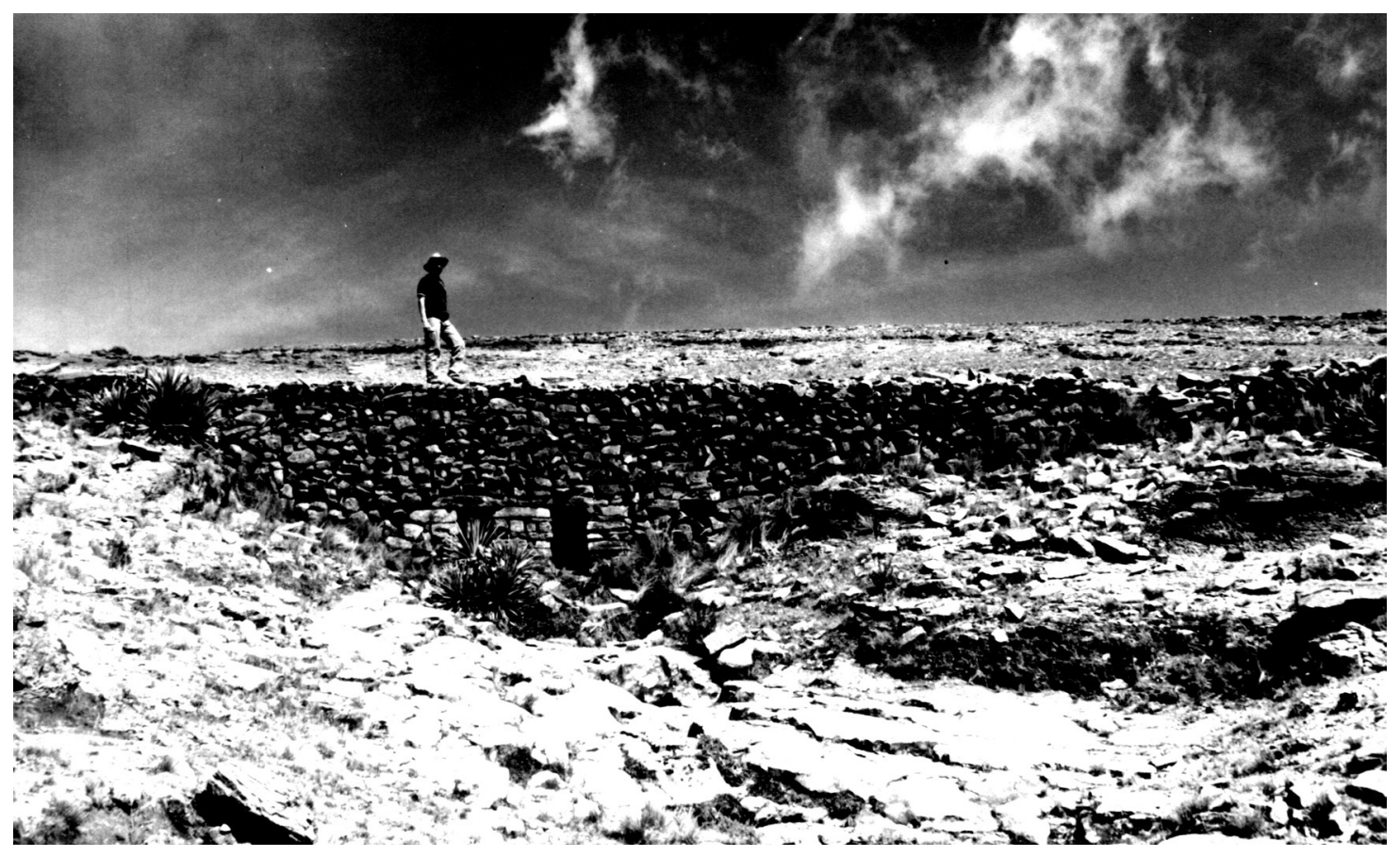

Figura 17: Rumichaca de Sama

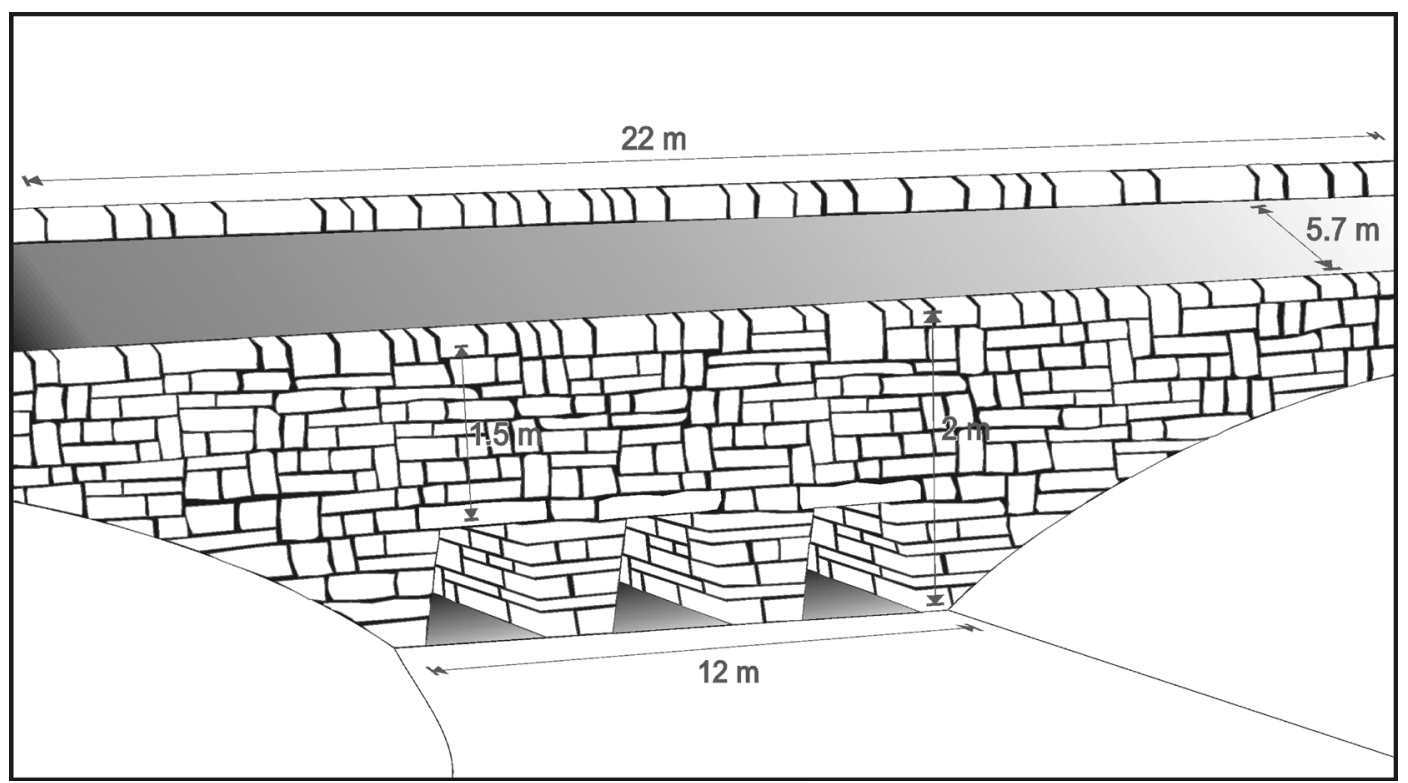

Figura 18: Rumichaca de Sama 
Folia Histórica del Nordeste, $\mathbf{N}^{0} 16$ (Resistencia, 2006) IIGHI, CONICET - IH, UNNE)

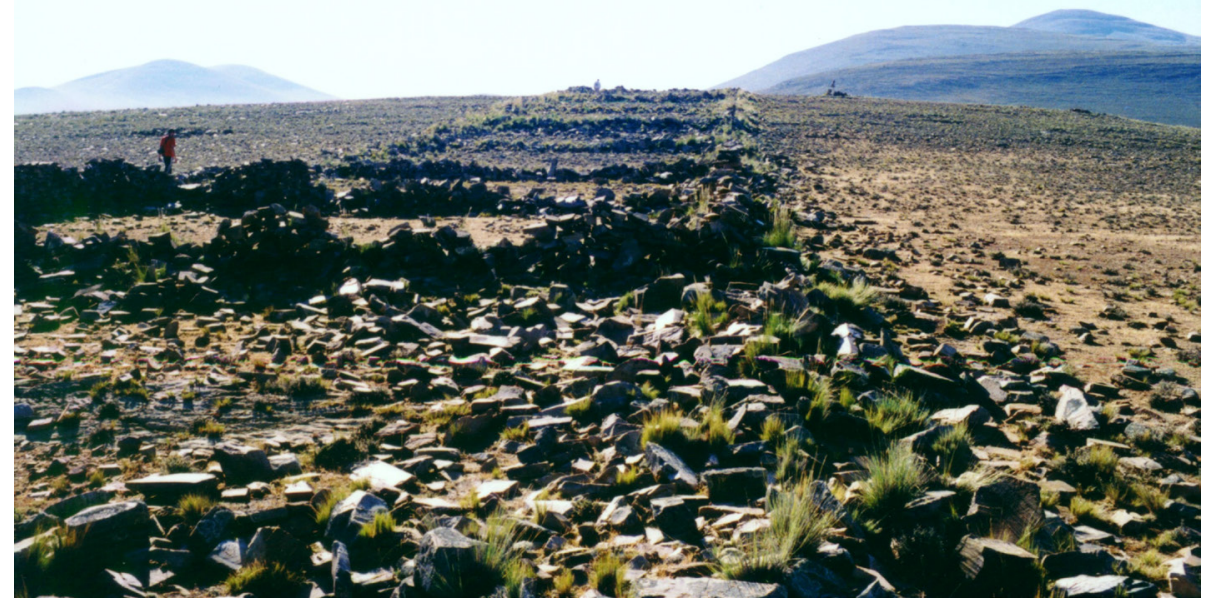

Figura 19: Tambo corrales agrupados y croquis de Tajsara

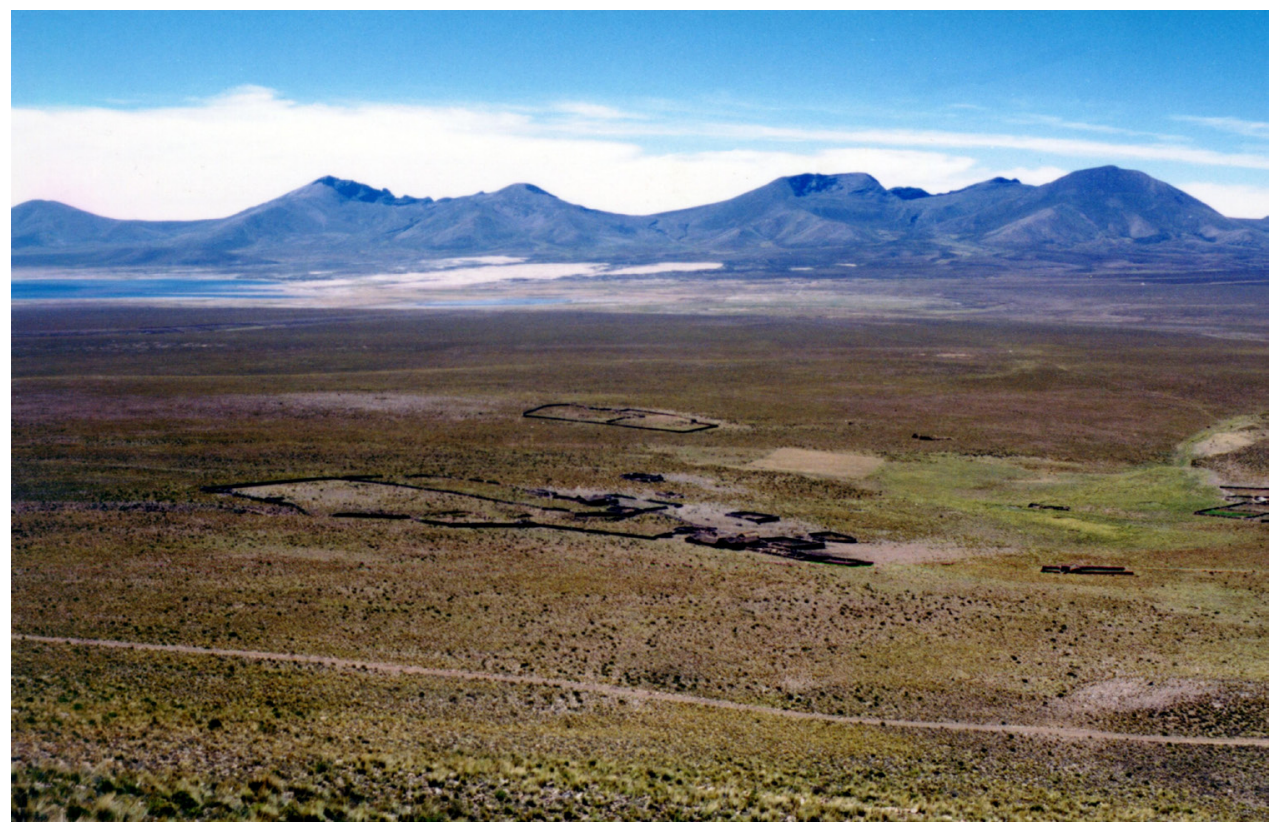

Figura 20: Tambo, corrales agrupados y croquis de Tajsara 
Folia Histórica del Nordeste, No 16 (Resistencia, 2006) IIGHI, CONICET - IH, UNNE)
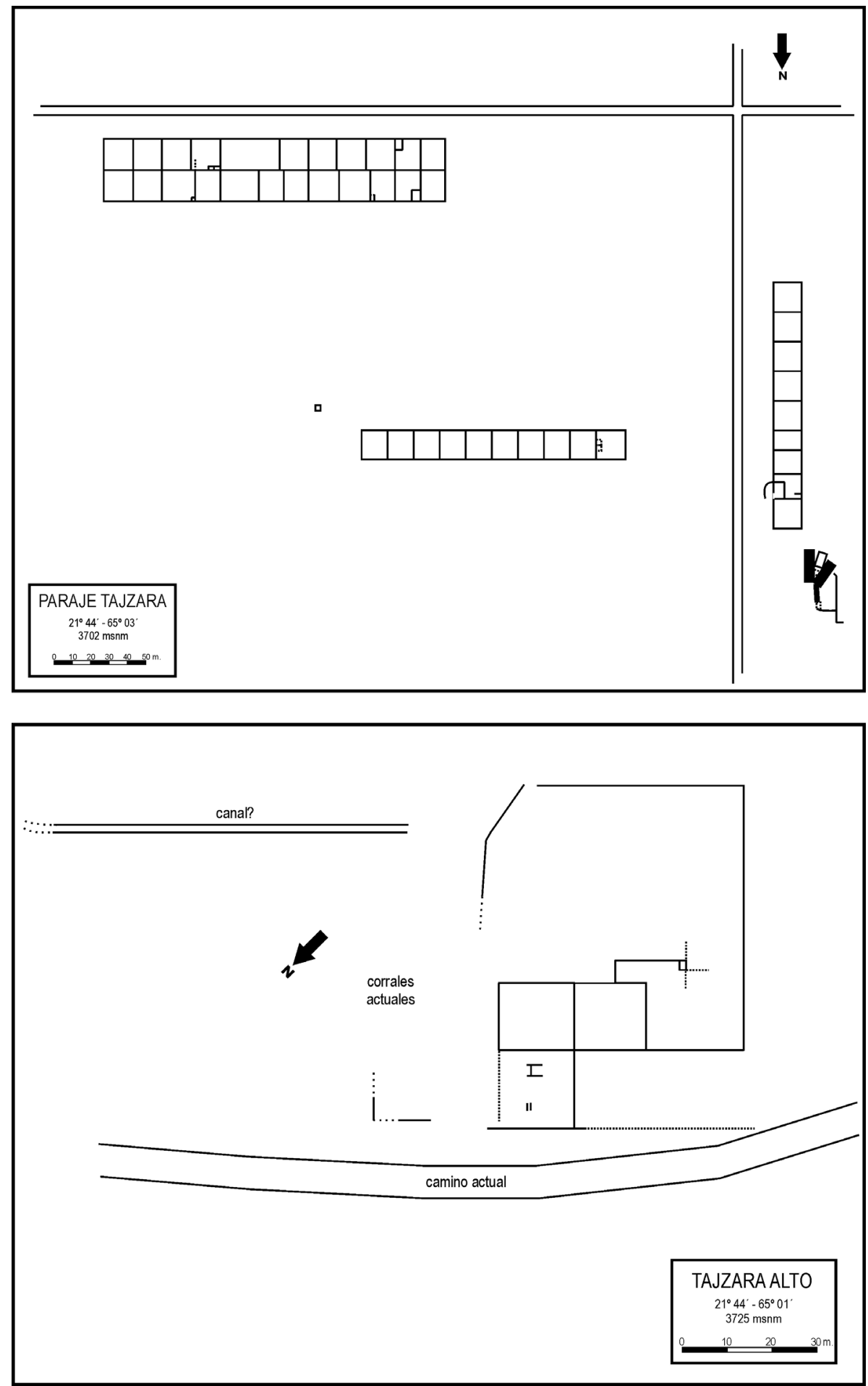

Figura 21: Tambo, corrales agrupados y croquis de Tajsara 
Folia Histórica del Nordeste, $\mathbf{N}^{0} 16$ (Resistencia, 2006) IIGHI, CONICET - IH, UNNE)

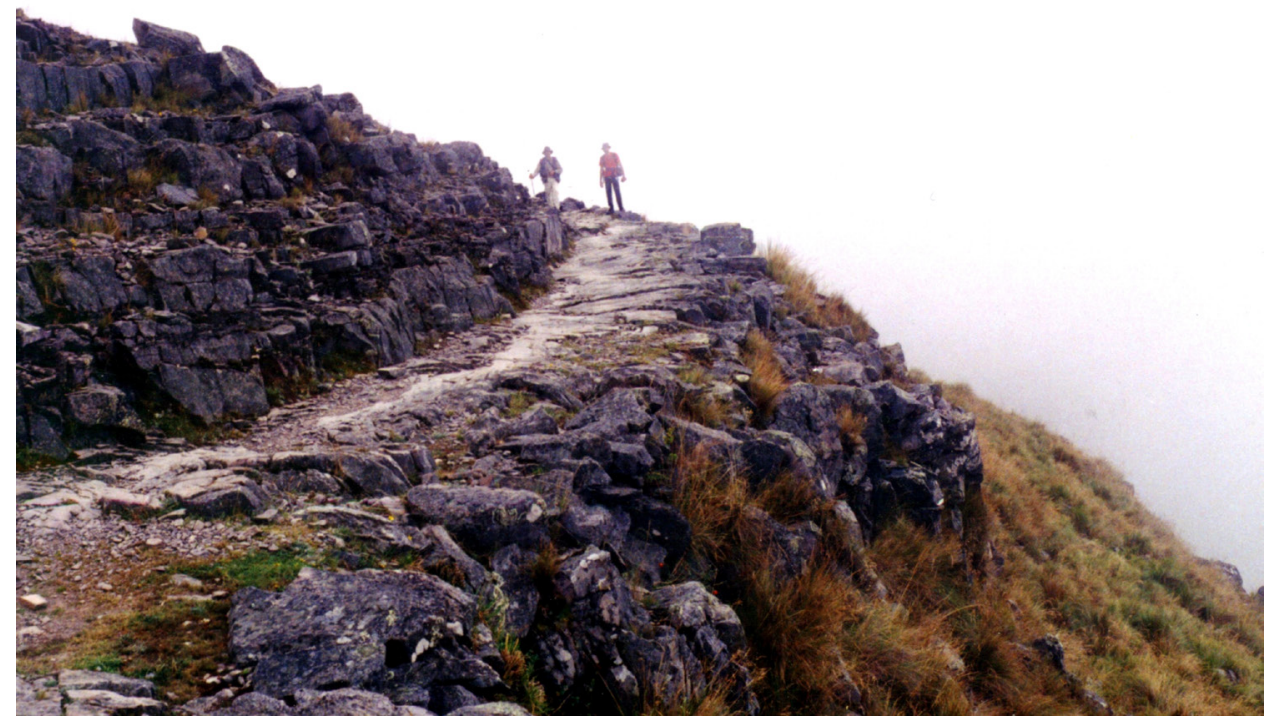

Figura 22: El Capacñan entre Tajsara y Calderillas (La Patanka)

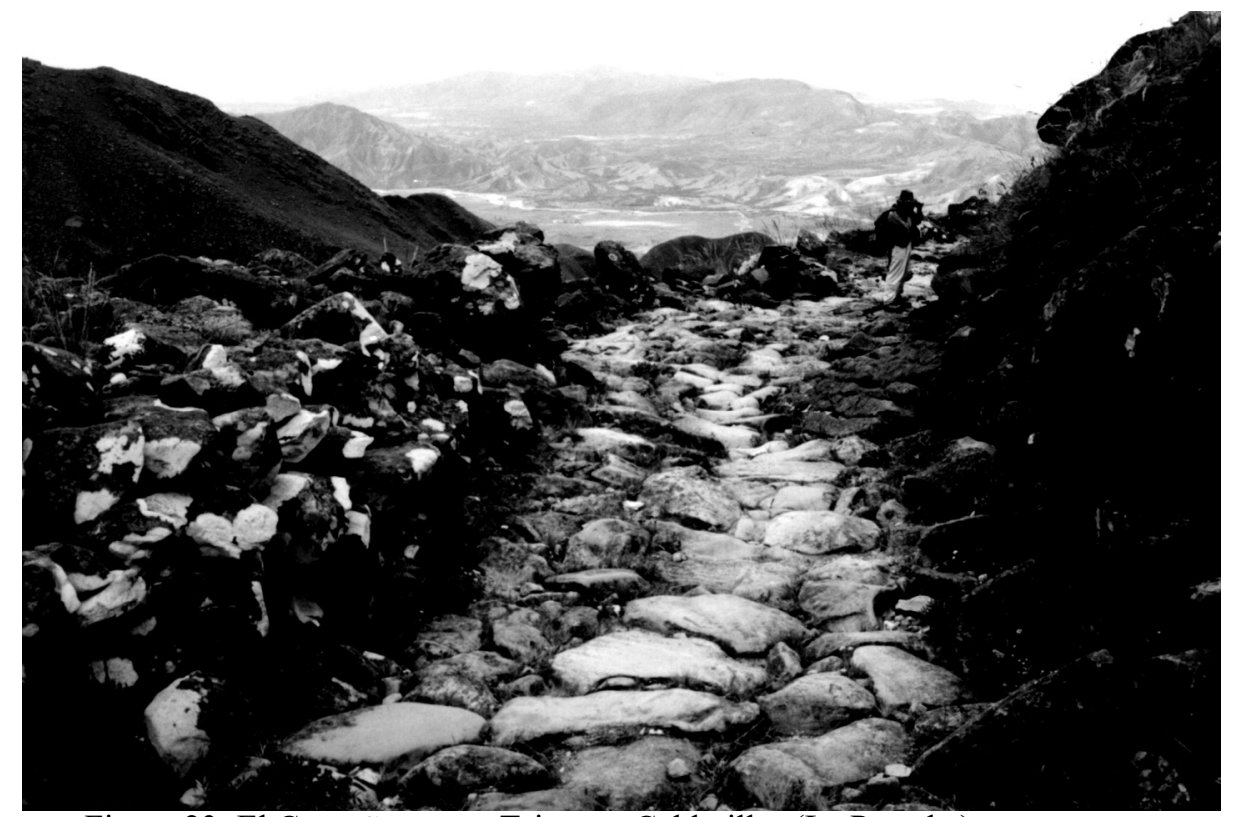

Figura 23: El Capacñan entre Tajsara y Calderillas (La Patanka) 
Folia Histórica del Nordeste, Nº 16 (Resistencia, 2006) IIGHI, CONICET - IH, UNNE)

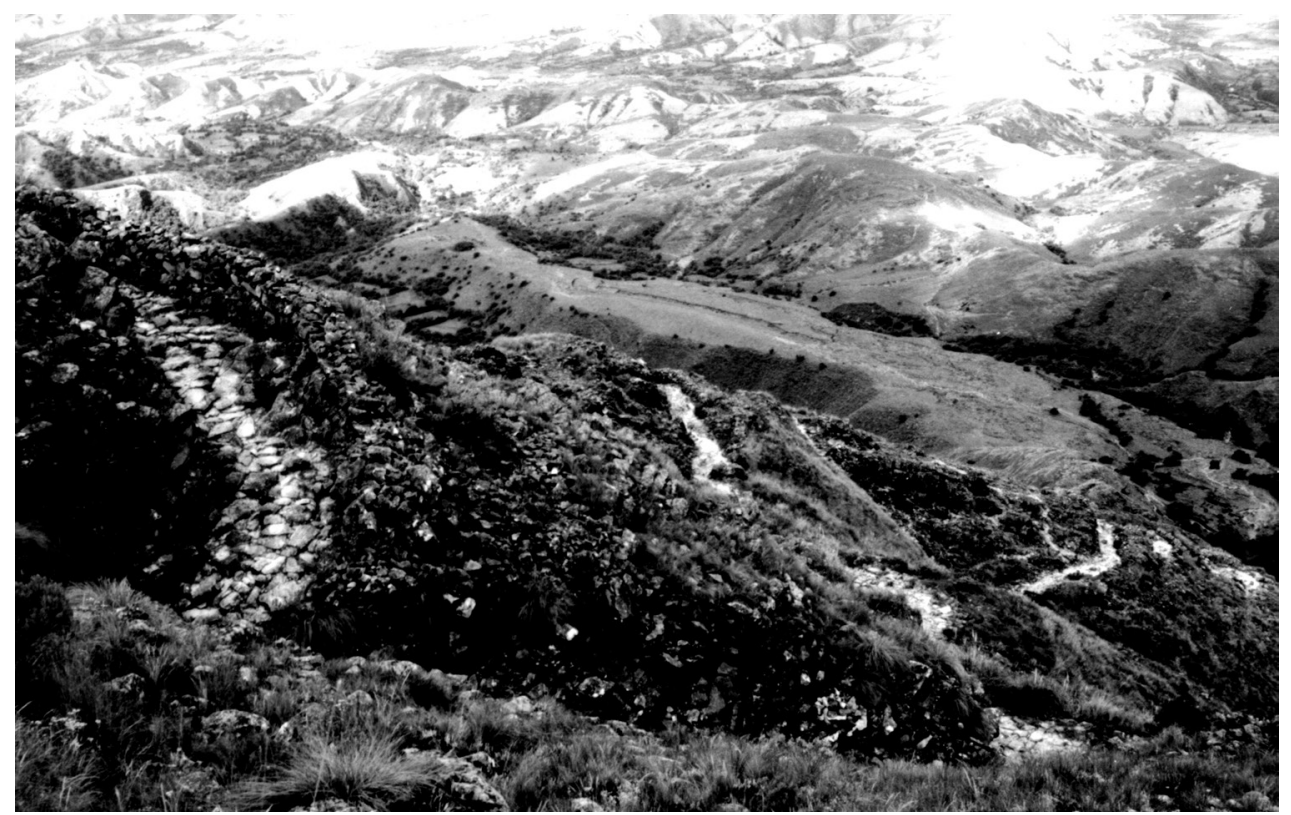

Figura 24: El Capacñan entre Tajsara y Calderillas (La Patanka)

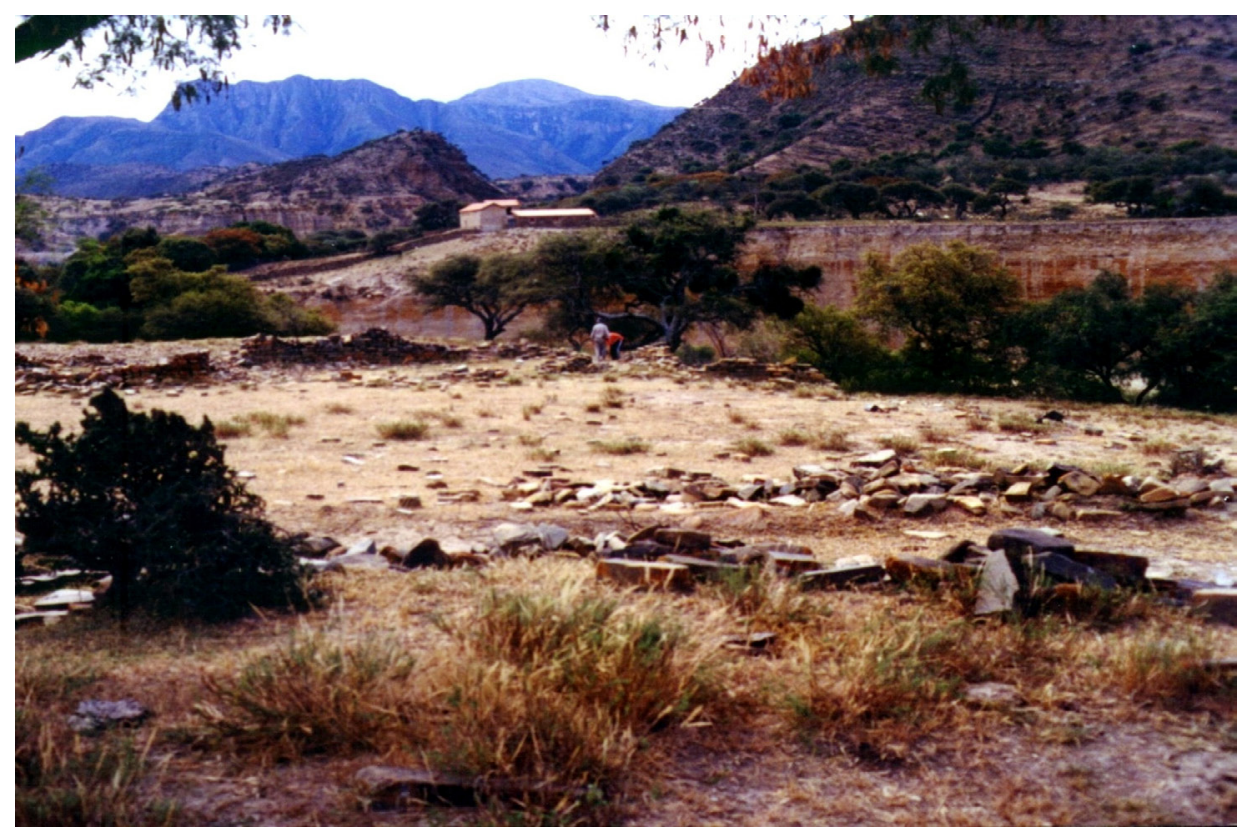

Figura 26: Segmento de Capacñam y chasquiwasi Cementerio 
Folia Histórica del Nordeste, $\mathbf{N}^{0} 16$ (Resistencia, 2006) IIGHI, CONICET - IH, UNNE)

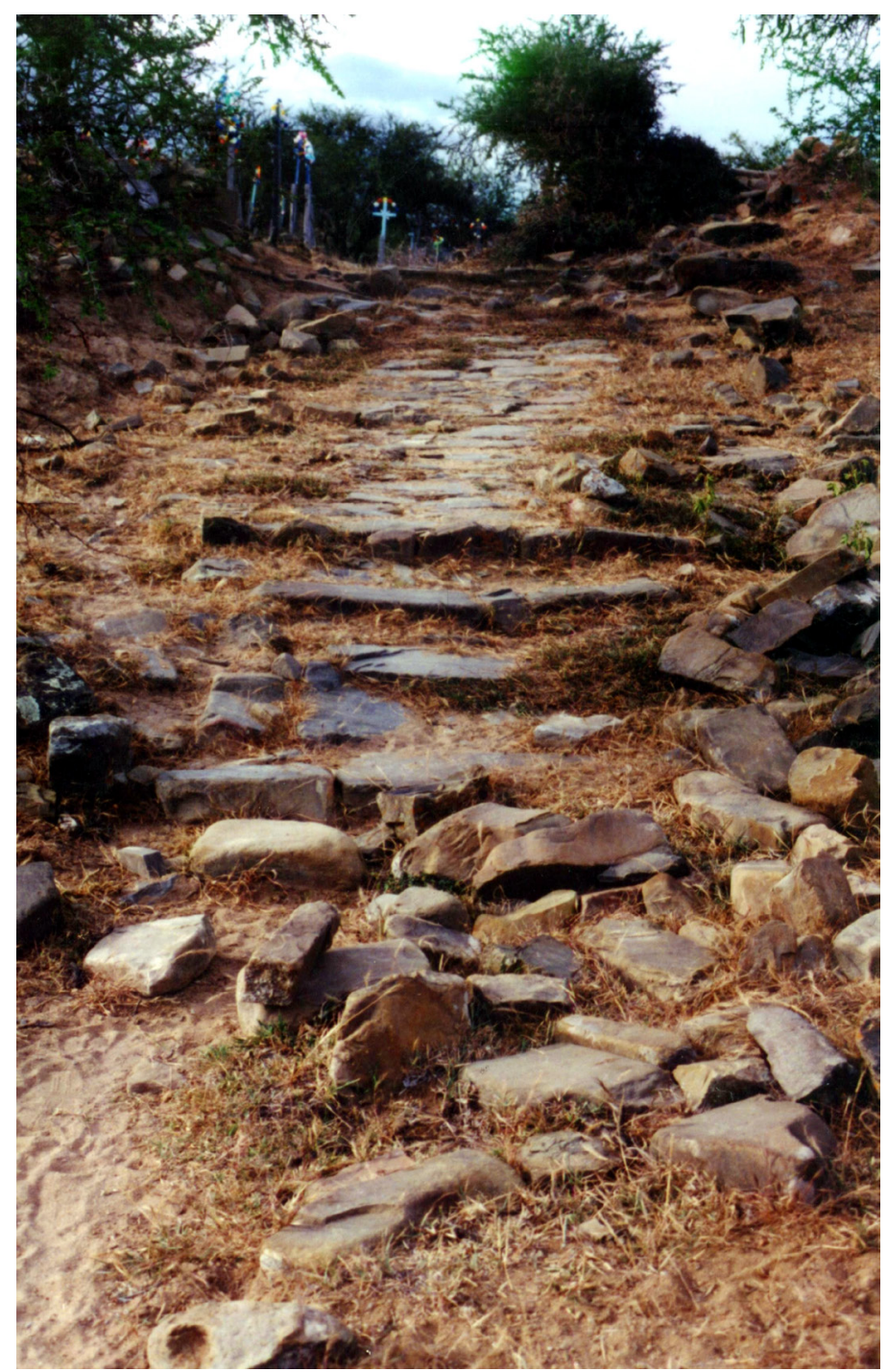

Figura 25: Segmento de Capacñam y chasquiwasi Cementerio 
Folia Histórica del Nordeste, $\mathbf{N}^{\circ} 16$ (Resistencia, 2006) IIGHI, CONICET - IH, UNNE)

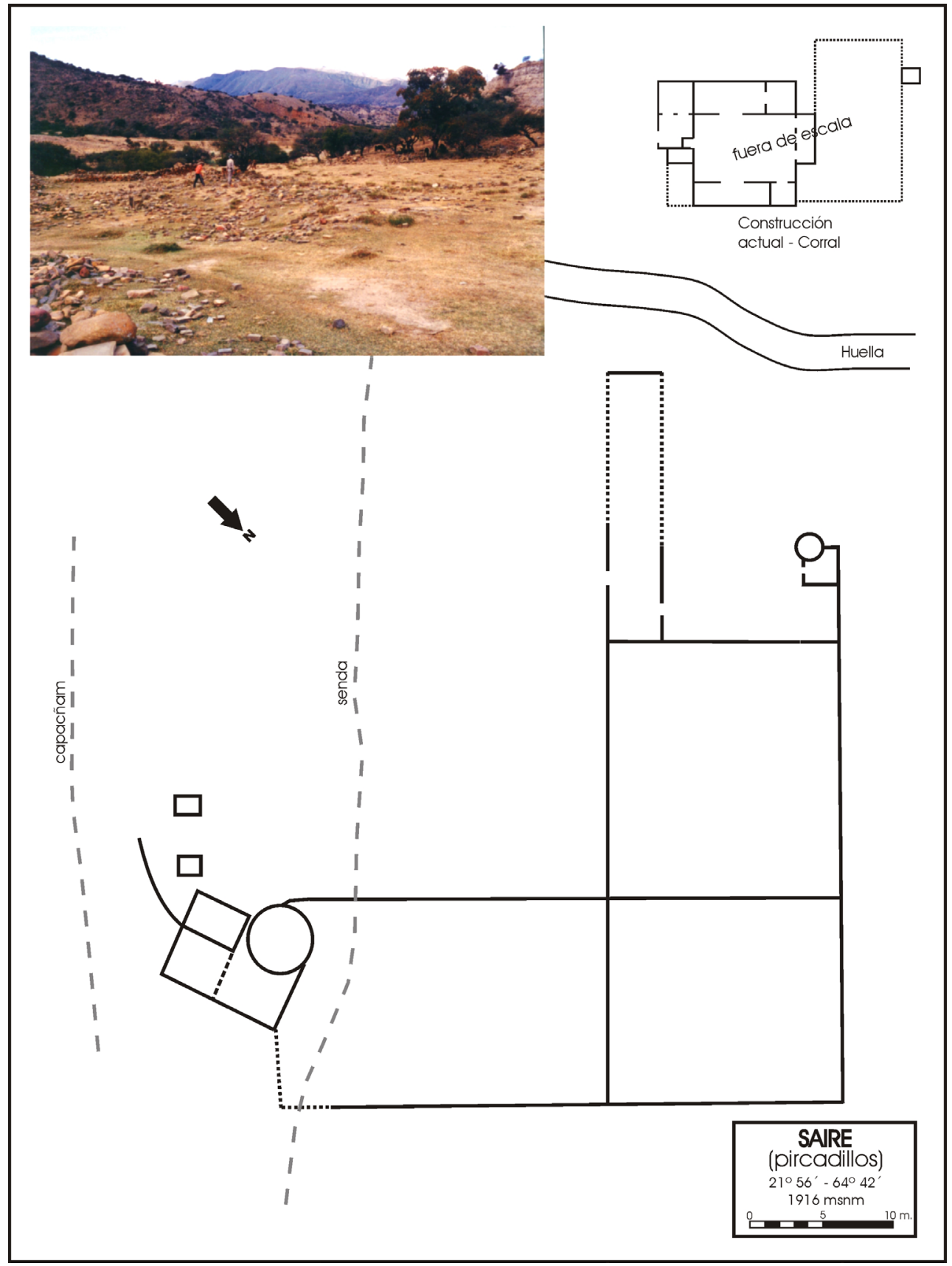

Figura 27: Croquis e imagen del tambo Saire 
Folia Histórica del Nordeste, Nº 16 (Resistencia, 2006) IIGHI, CONICET - IH, UNNE)

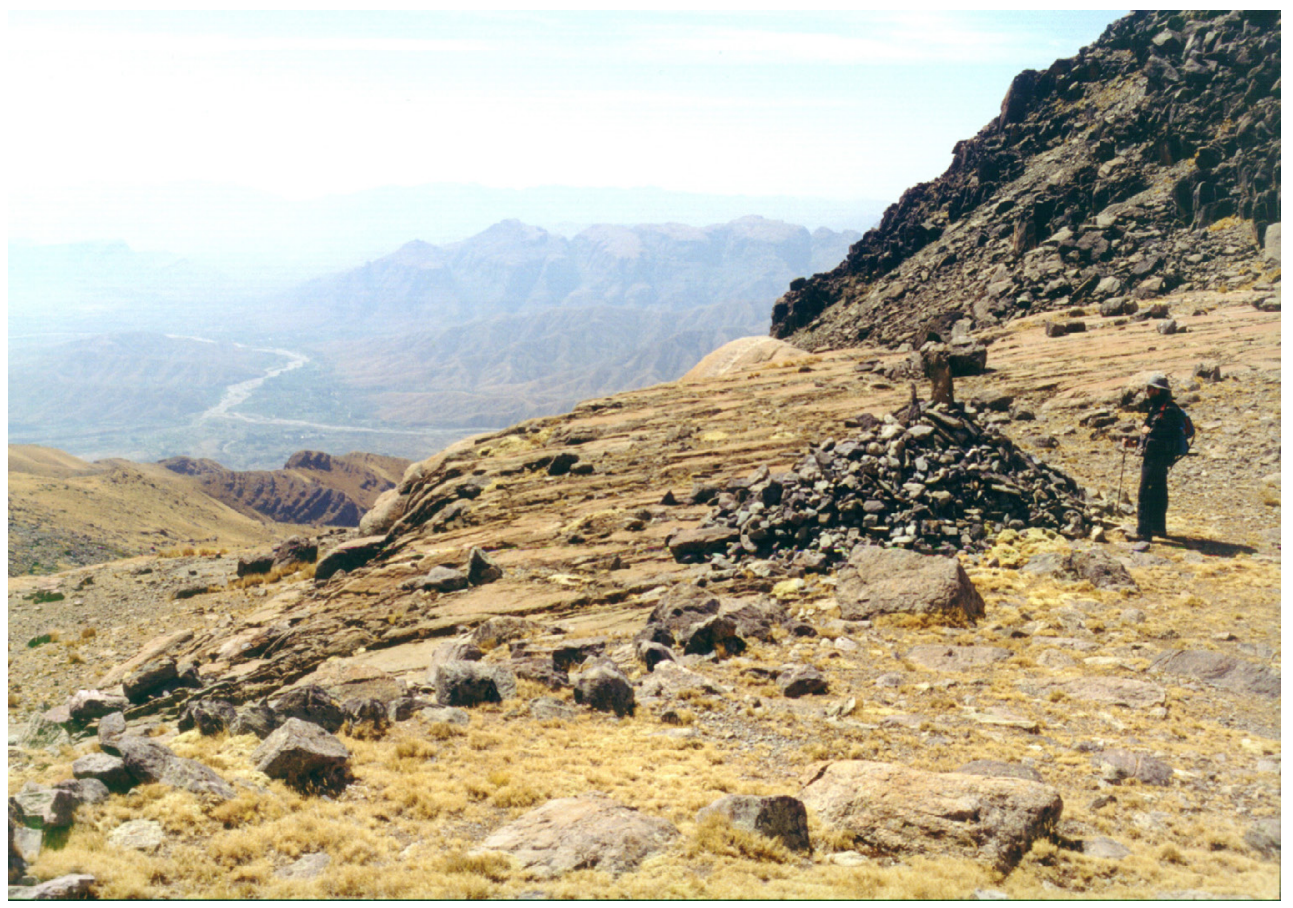

Figura 28: Apacheta Inka y segmentos de capacñam entre Torohuayco, Campanario y Camacho

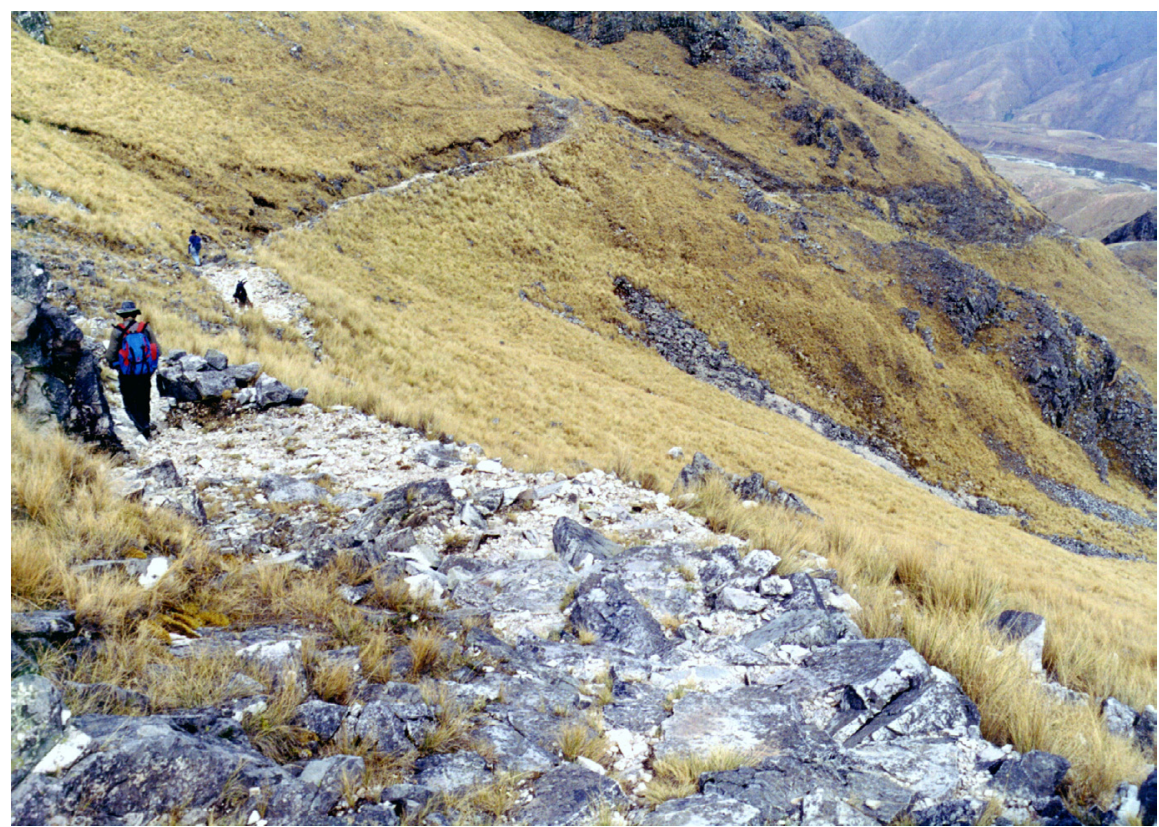

Figura 29: Apacheta Inka y segmentos de capacñam entre Torohuayco, Campanario y Camacho 
Folia Histórica del Nordeste, $\mathbf{N}^{0} 16$ (Resistencia, 2006) IIGHI, CONICET - IH, UNNE)

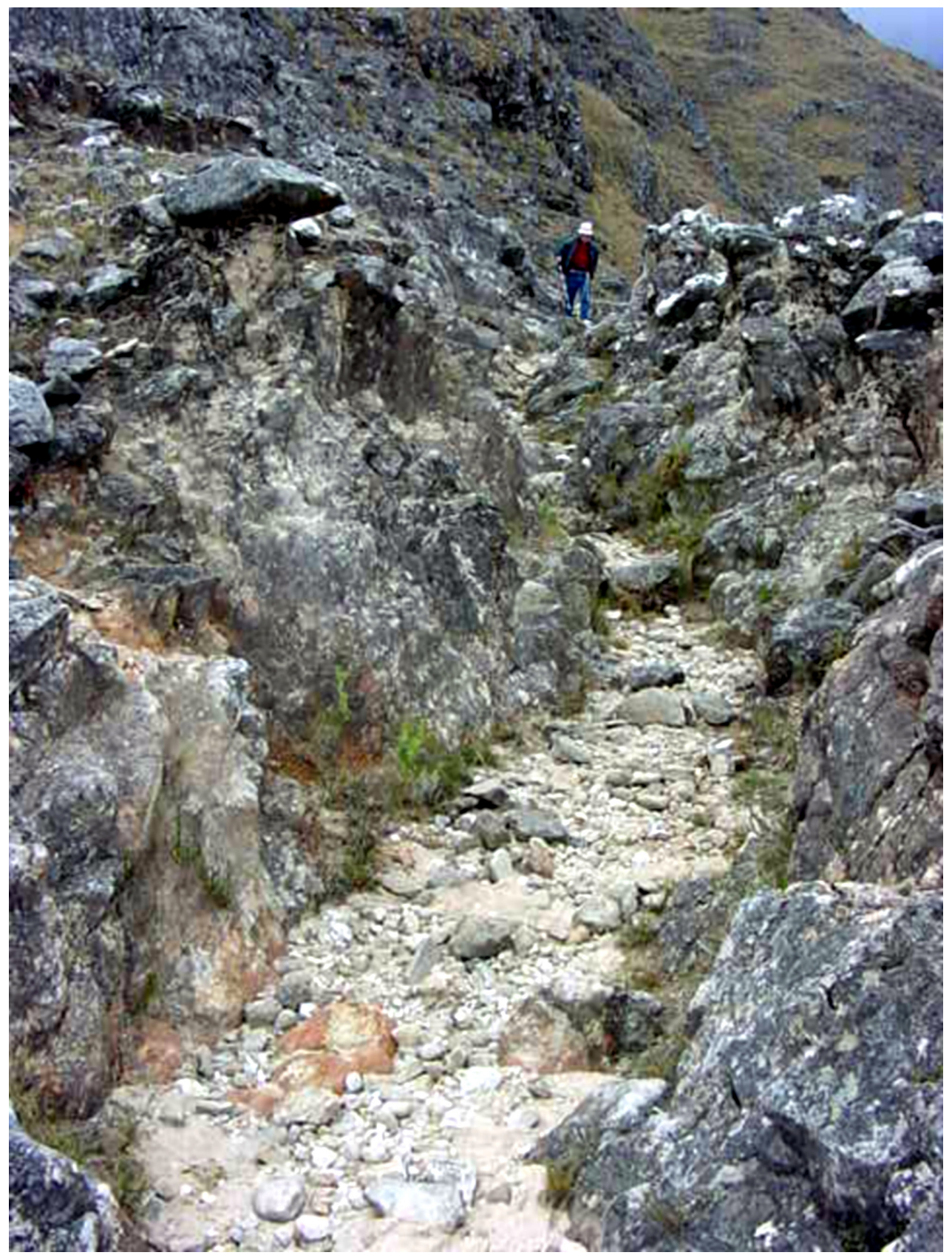

Figura 30: Apacheta Inka y segmentos de capacñam entre Torohuayco, Campanario y Camacho 
Folia Histórica del Nordeste, $\mathbf{N}^{0} 16$ (Resistencia, 2006) IIGHI, CONICET - IH, UNNE)

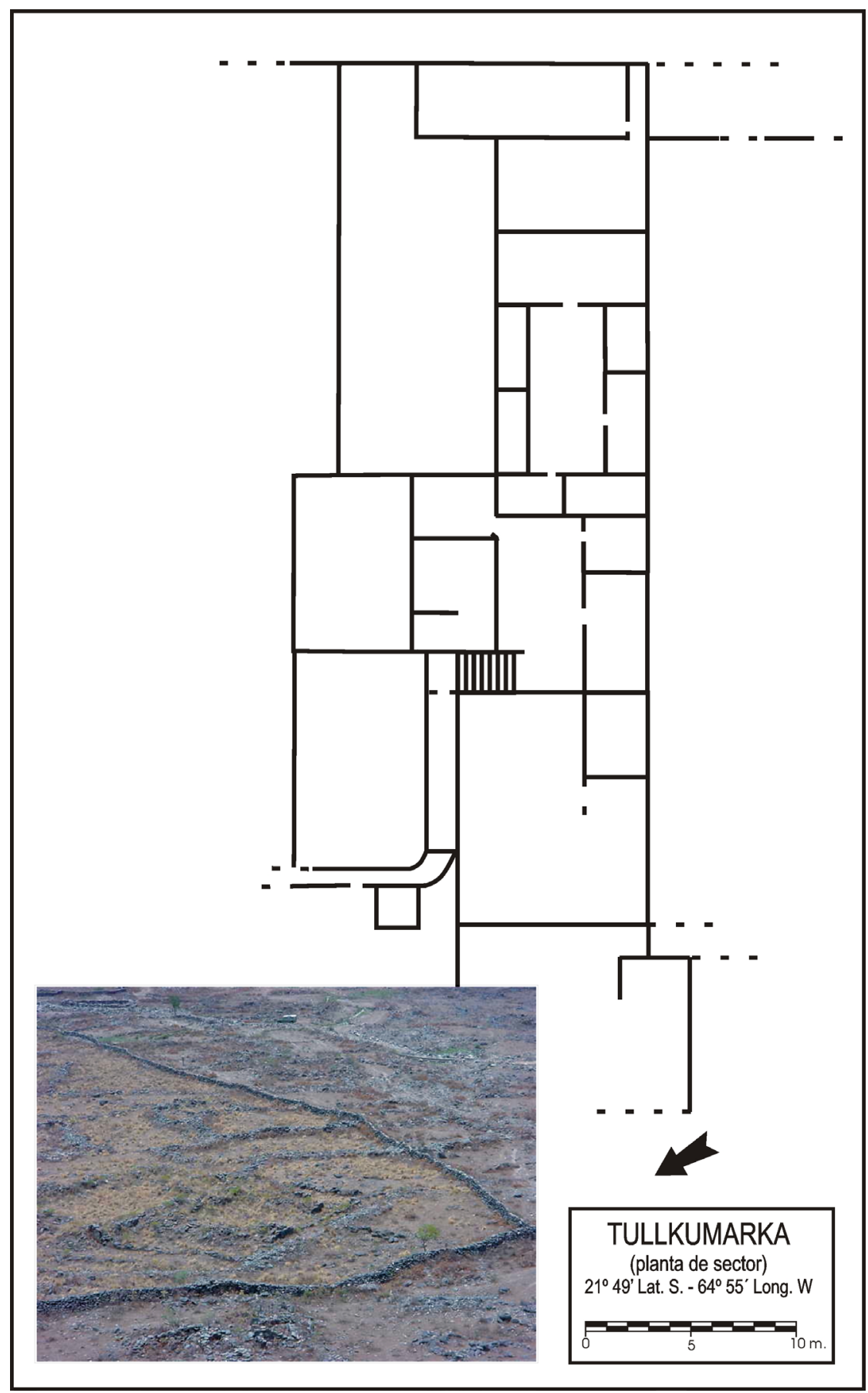

Figura31: Croquis e imagen del tambo Tullkumarca 
Folia Histórica del Nordeste, $\mathbf{N}^{\circ} 16$ (Resistencia, 2006) IIGHI, CONICET - IH, UNNE)

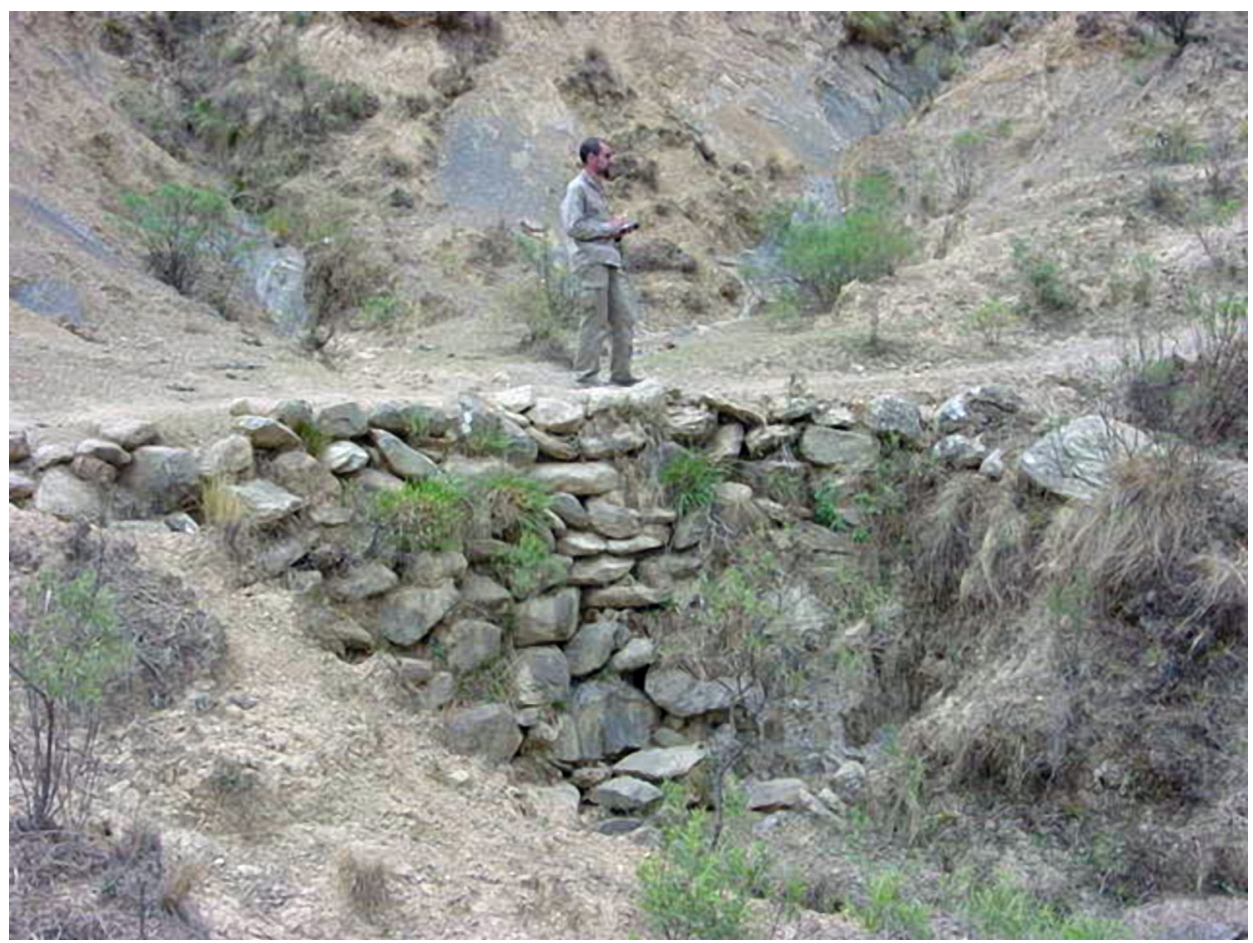

Figura32: Alcantarilla Inka entre Tullkumarca y Misca 
Folia Histórica del Nordeste, $\mathbf{N}^{0} 16$ (Resistencia, 2006) IIGHI, CONICET - IH, UNNE)

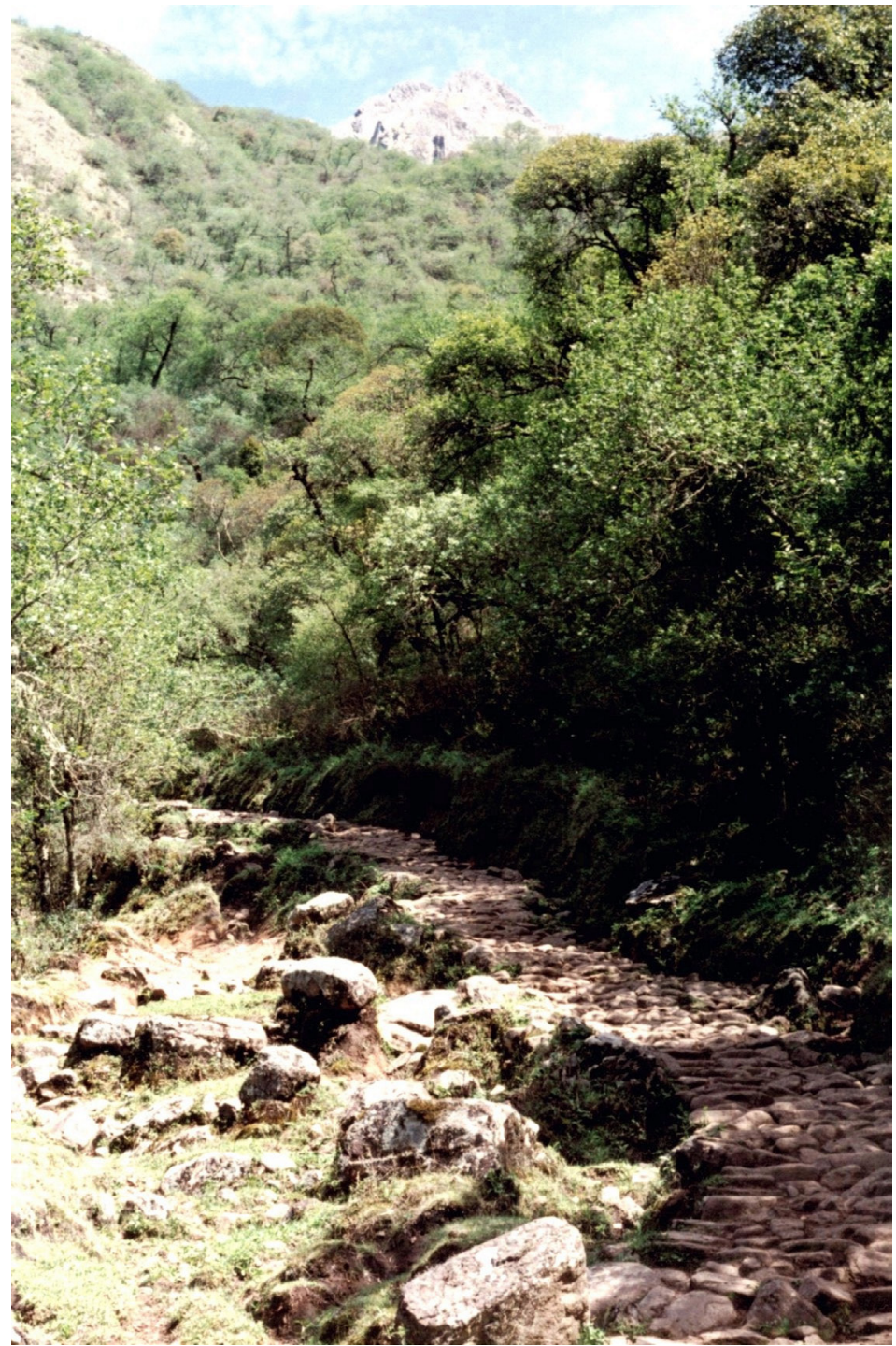

Figura33: El Capacñam en Tariquia y Fuete de Marquiri 
Folia Histórica del Nordeste, No 16 (Resistencia, 2006) IIGHI, CONICET - IH, UNNE)

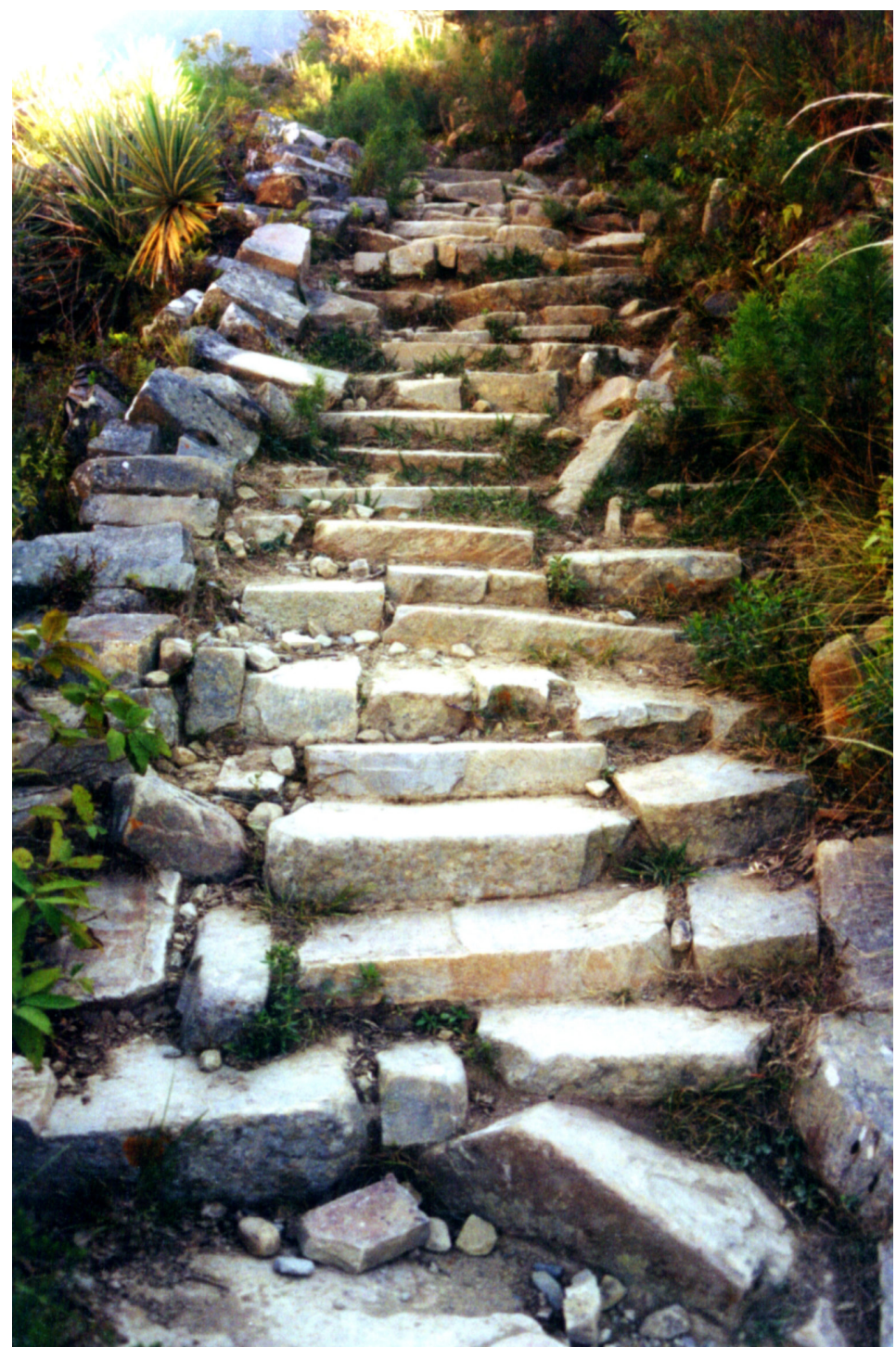

Figura34: El Capacñam en Tariquia y Fuete de Marquiri 


\section{Bibliografía}

Alconini, S. [1993] 2002. "Prehistoric Inka frontier in the Bolivien Chaco". Tesis. Univ. M. San Andrés. Bolivia

Arellano López, J. 1984. "La cultura Tarija. Aporte al conocimiento de los señoríos regionales del sur boliviano”. Arqueología Boliviana, No 1: 73-82. INAR, La Paz.

Barragán Vargas, M. 2001. Historia temprana de Tarija. Tarija. Bolivia.

Cieza de León [1553] 1947. Primera parte de la crónica del Perú. Biblioteca de Autores Españoles; T. 26. Madrid.

Darwin, C. 1962. "The voyage of the Beagle”. Garden City. New York. Doubleday.

Debenedetti, S. y E. Casanova. 1935. "Titiconte”. Public. Museo Antrop. y Etnolog. Serie A, III. Fac. Fil y Let. Universidad Nacional de Buenos Aires. Buenos Aires.

Delcourt, P. 2001. "Un inventario arqueológico preliminar en el Departamento de Tarija". Historia, ambiente y sociedad en Tarija. Bolivia. Eds S. Beck, N. Paniagua, D. Preston.

Universidad Mayor de San Andrés. La Paz. University of Leeds. Leeds, Reino Unido.

Espinoza Soriano, W. 1969. "El Memorial de Charcas: crónica inédita de 1582” Cantuta, 4, Universidad Nacional de Educación. Perú.

Espinoza Soriano, W. 1981. "El reino Aymara de Quillaca-Asanaque. siglos XV y XVI". Rev. Museo Nacional de Lima. XLV, 175-274. Lima.

Espinoza Soriano, W. 1986 "Los Churumatas y los mitmas Chichas orejones en los lindes del Collasuyu”. Rev. Histórica; XXXV. Lima.

Estete, M. de [1533] 1879. Relación del viaje que hizo el señor capitán Hernando Pizarro desde el pueblo de Caxamarca á Parcama y de allí á Jauca. Biblioteca de Autores Españoles; 26, Madrid.

Gade, D. 1972. "Bridge types in the central Andes". Annals of the Association of American Geographers; 62, No1. Lawrence, Kansas.

Gandia, Enrique de 1935. Historia de Santa Cruz de la Sierra. Una nueva república en Sud América. Buenos Aires. Talleres Gráficos Argentinos de L. J. Rosso.

Gerbi, A. 1944. Caminos del Perú. Banco de Crédito del Perú. Lima.

Guaman Poma de Ayala, P. [1613] 1936. "Nueva crónica y buen gobierno”. Travaux et Mémoires de I'Institut d'Ethnologie. T XXIII. París.

Herrera y Tordesillas, A. [1615] 1952. "Historia General de los hechos de los castellanos en las islas y tierra firme del mar océano”. Tomo II.. Ed. Nicolás Rodríguez Franco. Madrid.

Hyslop, J. 1984. The Inka road System. Studies in Archaeology. Orlando, Florida. Academic Press, INC.

Hyslop, J. 1992. “Ghapaqñan, el sistema vial inkaico”. Inst. Andino de Estudios Arqueológicos. Lima.

Lee, V. 1992. "Seven Inka pucarás on the bolivian frontier". 31 st. Annual Meeting. Inst. of Andeans Studies. Berkeley. California.

Levillier, R. 1926. "Nueva Crónica de la Conquista del Tucumán”. Colección de Publicaciones Históricas del Congreso Argentino. 2 vols. Madrid.

Lizárraga, R. de 1999. Descripción del Perú, Tucumán, Río de La Plata y Chile Union Académique Internationale. Prólogo de Edberto O. Acevedo. Academia Nacional de la Historia. Buenos Aires.

Márquez Miranda, F. 1939. “Cuatro viajes al más remoto Noroeste argentino”. Rev. Mus. La Plata (NS), Antrop. I. Buenos Aires.

Maeder, E. 1996. Historia del Chaco. Buenos Aires. Ed. Plus Ultra. 
Mellafé, R 1965. "La significación histórica de los puentes en el virreynato peruano del siglo XVI”. Historia y Cultura; Vol.1, $\mathrm{N}^{\circ} 1$. Lima.

Metraux, A. 1933. “Contribución a la arqueología boliviana”. Journal de la Société des Américanistes. NS, T. 25. París.

Meyer, A. y C. Ulbert. 1997. "Inka archaeology in southeastern Bolivia: Some aspect of the Samaipata project. Tawantinsuyu; Vol. 3. Canberra.

Muñoz Reyes, J. 1980. Geografía de Bolivia. Academia Nacional de Ciencias de Bolivia. La Paz.

Nielsen, A. 1997. Tiempo y cultura material en la Quebrada de Humahuaca. San Salvador de Jujuy, Jujuy.

Nielsen, A. 1998. "Tráfico de caravanas en el sur de Bolivia: observaciones etnográficas e implicancias arqueológicas". Rel. Soc. Arg. Antropología. Vol. XXII-XXIII; Buenos Aires.

Nordenskiöld, E. 1917. "The Guarani invasion of the Inca empire in the sixteenth century". The Geographical Review, Vol. IV, 2. New York.

Nordenskiöld, E. 1924. Forschungen und Abenteuer in Sudamerika. Stuttgart, Alemania.

Pizarro, H [1533] 1917. Relación de los señores Oydores de la Audencia Real de S. M. Col. Urteaga; T. III. Lima.

Posnansky, A 1945. Tiahuanacu, cuna del hombre americano. 2 vols. New York.

Presta, A. M. 1997. “La población de los Valles de Tarija, siglo XVI”. El Tucumán Colonial y Charcas. Tomo I. Facultad de Filosofía y Letras. UBA. Buenos Aires

Presta, A. M. 2001. "Hermosos, fértiles y abundantes". Los valles centrales de Tarija y su población en el siglo XVI. Historia, ambiente y sociedad en Tarija. Bolivia. La Paz. Eds S. Beck, N. Paniagua, D. Preston. Universidad Mayor de San Andrés. La Paz. University of Leeds. Leeds, Reino Unido.

Pulgar Vidal; 1946. Historia y geografía del Perú. Las ocho regiones naturales del Perú. Universidad Nacional Mayor de San Marcos. Lima.

Raffino, R. A. 1981-2 Los Inkas del Kollasuyu. $2^{\text {a }}$ Ed. corregida y aumentada. La Plata. Edit. Ramos Americana.

Raffino, R. A. 1988. Poblaciones indígenas en Argentina. Urbanismo y proceso social precolombino. (2da. Ed. 1991). Buenos Aires. TEA Ed

Raffino, R. A. 1993 Arqueología, historia y urbanismo del altiplano andino. Buenos Aires. Ediciones Corregidor.

Raffino, R. A. 1995 "Inka road research and Almagro's road between Argentina and Chile”. Tawantinsuyu. Vol. 1. Canberra.

Raffino, R. A. 2004. El Shincal de Quimivil. Catamarca .Ed. Sarquis.

Raffino, R. A., R. Alvis, D. Olivera, J. Palma.1986 "La instalación Inka en la sección andina meridional de Bolivia y extremo boreal de Argentina”. Comechingonia 4, número especial: 63-131. Córdoba.

Raffino, R. A., A. Nielsen y R. J. Alvis 1991 "El dominio Inka en dos secciones del Kollasuyu: Aullaguas y Vallegrande" (Altiplano de Bolivia y Oriente de Humahuaca). Comechingonia, 9, número especial: 97-151, Córdoba.

Raymondi (Raimondi), A. 1908. "Itinerario de los viajes de Raimondi en el Perú”. Boletín de la Sociedad Geográfica de Lima, Vol. 10, 1-3. Lima.

Regal, A. 1936. Los caminos del Inca. Sanmarti. Lima.

Regal, A. 1972. Los puentes Inca en el antiguo Perú. Imp. Gráfica Industrial. Lima.

Renard-Casevitz, F. Th. Sainés y A. Taylor. 1988. “Al Este de los Andes. Relaciones entre las sociedades andinas y amazónicas entre los siglos XV y XVI”. Ed. Abya-Yala e Inst. Francés de Estudios Andinos. T. I. Lima-Quito. 
Rosen, E. 1957 “Un mundo que se va” Fundación M. Lillo. 1. Universidad Nacional de Tucumán. Tucumán.

Saignes, Thierry. 1985 Los Andes orientales, historia de un olvido. Instituto Francés de Estudios Andinos. CERES-IFEA. Cochabamba.

Salas, Alberto M.. 1945. "El Antigal de Ciénaga Grande”. Public. del Museo Etnográfico. Serie A, V. Fac. Filosofía y Letras. Universidad Nacional de Buenos Aires.

Sanginés Rojas, G. 1957. “El camino Incaico de Taquesi”. Arqueología Boliviana. Biblioteca Paceña. La Paz. Alcaldía Municipal.

Schmieder, O. 1924. "Condor huasi, eine befestigte Siedlung der Inkas im sudlichen Bolivien" Geographischer Anstal. Heft 9/10. Gotha.

Service, E. 1971. Primitive social organization, an evolutionary perspective. 2da.Ed. New York. Randon House.

Squier, G [1863-65] 1974. Perú, incidents of travel and exploration in the land of the Incas. New York . La Paz (edic. en español) Los Amigos del Libro.

Walter, H. 1959. “Die ruine Pucará de Oronotá (Südost Bolivien)”. Baessler Archiv. Neue Folge. Band. VII, Heft 2. Berlin.

Xerez, F. de [1534] (1917). “Relación de la conquista del Perú”. Col. Urteaga, T. V. Lima.

\section{Resumen}

Se entregan las recientes investigaciones sobre instalaciones Inka y segmentos inéditos del llamado «Camino Inka de la Sierra». Este es el gran capacñam que parte desde la Aukaipata del Cuzco hacia el Kollasuyu, pasando por Rajchi, Hatumcolla, Chucuito, Desagüadero, Andamarca, Oma Porco, Aullagas y Tupiza hasta llegar a Chuquiago del Valle de Suipacha. En este centro el camino se divide en dos ramales; uno continúa directamente hacia el S. por la quebrada de Talina en los establecimientos Inka de Chipihuaico y Chagua hasta llegar a Calahoyo, en la actual frontera del altiplano argentino-boliviano. Estas secciones del capacñam, sus tampus, puentes, guarniciones defensivas e instalaciones agrícolas fueron reconocidas en misiones subsidiadas por National Geographic Society (R. Raffino; Grant 2834/1984 y Grant 4430/1991) y publicadas sucesivamente en 1986, 1991, 1993 y 1995. A ellas se les incorpora, siempre bajo el auspicio de esta institución, los trabajos realizados en el extremo meridional boliviano y boreal del NOA (R. Raffino; Grant $7126 / 2001)$.

Las secciones investigadas en este proyecto son aquellas que comunican el altiplano boliviano por donde transcurre el capacñam con estos ramales que se desvían hacia el levante y por la Cordillera de los Chichas, los valles de Tarija y penetran en las yungas del S. boliviano y del extremo boreal argentino, trasponiendo hacia el oriente los $64^{\circ}$.

Dos problemas se plantean al realizar investigaciones en estas regiones. El primero consiste en discernir, entre una multitud de caminos segmentados en ramales discontinuos, cuáles obedecen a factura Inka. La segunda dificultad es la rigurosidad del paisaje andino, ya que la mayoría de los registros arqueológicos están situados en paisajes con altitudes propias de las montañas de la Cordillera Central de Bolivia y en la Sierra de Santa Victoria de Argentina, lo que ha hecho posible la buena conservación de los vestigios arqueológicos.

$<$ Arqueología y etnohistoria $><$ Inka $><$ Bolivia $><$ Norte de Argentina $>$ 


\section{Summary}

We offered the recent land investigations on Inka sites and unpublished segments of the "Camino Inka de la Sierra". This is the great capacñam, that starts in the Aukaipata of Cuzco and goes to the Kollasuyu through Rajchi, Hatumcolla, Chucuito, Desagüadero, Andamarca, Oma Porco, Aullagas and Tupiza until arriving at Chuquiago in the Suipacha's valley. In this important administrative center founded by the Inka the road is divided in two branches; one of them continues directly towards the South by Talinain the Inka Chipihuaico and Chagua until arriving at Calahoyo, in the actual frontier of the Argentinean-Bolivian plateau. These sections of capacñam, its tampus, bridges, defensive and agricultural sites, were recognized in missions supported by National Geographic Society (R. Raffino; 2834/1984 and Grant 4430/1991) and published successively in 1986, 1991, 1993 and 1995. Always sponsored by this institution, the works continued in the southern Bolivia and Northwest Argentina (R. Raffino; Grant 7126/2001).

The Inka road sections researched in this project are indeed those that communicate the Bolivian plateau with these branches recently recognized, that turned towards the East and cross the "Chichas" towards the Tarija's valley and arrived to the yungas in the southern Bolivia and Northwest Argentina, transposing the $64^{\circ} \mathrm{LW}$.

We must consider two problems while doing researches in these regions. First, to discriminate, which of the several roads segmented in discontinuous branches were made by Inka. The second one, was the severity of the Andean landscapes, because most of the archaeological sites were located in high altitudes of the "Cordillera Central de Bolivia" and the "Sierra de Santa Victoria" of Argentina. Nevertheless, this circumstance has allowed the optimal conservation until the present of the archaeological vestiges and the pre and post Hispanic roads with its tipological variants.

$<$ Inka $><$ Archaeology and etnohistory $><$ Bolivia $><$ Norte of Argentina $>$ 